BANK OF CANADA

BANQUE DU CANADA

Staff Working Paper/Document de travail du personnel $-2020-37$

Last updated: September 14, 2020

\title{
Predicting Payment Migration in Canada
}

by Anneke Kosse, Zhentong Lu and Gabriel Xerri

Financial Stability Department

Bank of Canada, Ottawa, Ontario, Canada K1A 0G9

akosse@bankofcanada.ca, zlu@bankofcanada.ca, gxerri@bankofcanada.ca

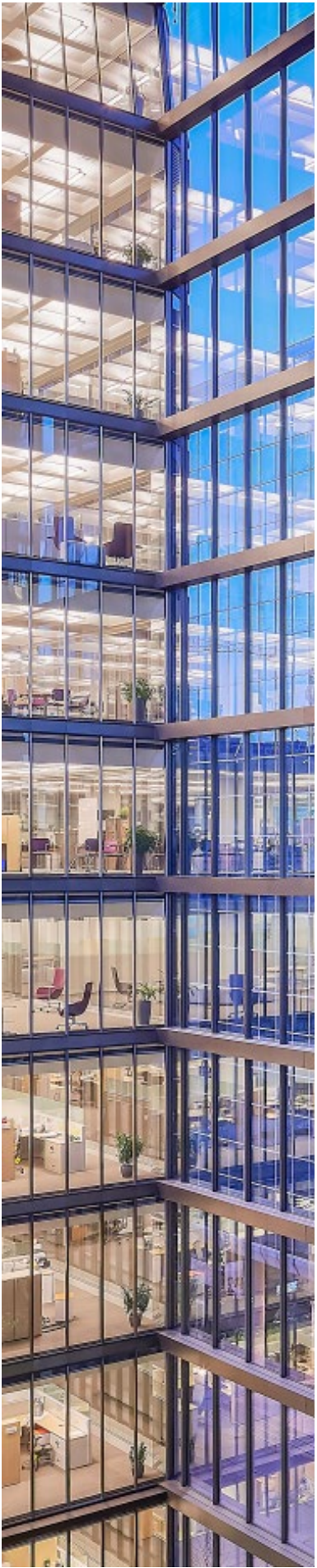

Bank of Canada staff working papers provide a forum for staff to publish work-in-progress research independently from the Bank's Governing Council. This research may support or challenge prevailing policy orthodoxy. Therefore, the views expressed in this paper are solely those of the authors and may differ from official Bank of Canada views. No responsibility for them should be attributed to the Bank. 


\section{Acknowledgements}

The authors thank Nicholas Kazaka and Francis Bolton for excellent research assistance; Lana Embree, Francisco Rivadeneyra, Kevin Wai and two anonymous referees for the thorough read and detailed comments; and Wilko Bolt, James Chapman, Charles Kahn, Wade McMahon, Alessandro Pioli, Christopher Reid, and Alexander Ueberfeldt for useful suggestions. We also thank the following for their comments: participants at the 17th Bank of Finland Payment and Settlement System Simulation Seminar, the Quarterly Joint Payments Canada and Bank of Canada Research Workshop, the 6th Annual Payments Canada and Bank of Canada Payments Research Symposium, the Bank of Canada's BBL Seminar, and the 2020 Annual Meeting of the Central Bank Research Association. All errors are ours. The views expressed are ours and do not necessarily reflect those of the Bank of Canada. 


\section{Abstract}

Canada currently has two core payment systems for processing funds transfers between financial institutions: the Large Value Transfer System (LVTS) and the Automated Clearing Settlement System (ACSS). These systems will be replaced over the next years by three new systems: Lynx, the Settlement Optimization Engine (SOE) and the Real-Time Rail (RTR). We employ historical LVTS and ACSS data to predict the demand for the future systems. The results show that small-value LVTS payments will likely migrate to SOE. Also, in the short run, about CAD 10,000 billion of LVTS and ACSS payments (per year) is anticipated to migrate to the RTR if not subject to maximum transaction values. These migration patterns raise important policy questions, such as whether the future systems should be subject to value caps and/or higher collateral requirements.

Topics: Financial stability; Financial institutions; Financial services; Financial system regulation and policies; Payment clearing and settlement systems

JEL codes: C3, E42, G1, G2 


\section{Introduction}

Every day, about 30 million financial transactions take place in Canada, having a total daily value of more than CAD 210 billion. These transactions are the result of consumers, businesses and government organizations purchasing goods and services, making financial investments and transferring funds. Having safe and robust payment systems in place for the processing of these transactions is crucial to overall financial stability. Canada currently has two core payment systems for processing funds transfers between financial institutions: the Large Value Transfer System (LVTS) and the Automated Clearing Settlement System (ACSS) 11 However, Payments Canada - the owner and operator of LVTS and ACSS - is undertaking a large initiative to modernize the Canadian payments ecosystem $2^{2}$

Lynx, SOE and RTR will differ from LVTS and ACSS in numerous ways, such as the speed with which funds are transferred and the amount of liquidity required by banks to backup these transactions. As a result of this, the migration of current payments into the new systems might introduce payment system risks. For example, a migration of large LVTS payments into SOE could lead to large end-of-day credit exposures, since SOE is based on end-of-day instead of real-time settlement. Also, a migration of particularly large LVTS transactions into RTR might make RTR more susceptible to fraud risks as RTR is likely to be subject to less stringent cyber security controls while having a broader access regime than Lynx.

\footnotetext{
${ }^{1}$ See Kosse et al. (2020) for the core characteristics of LVTS and ACSS.

${ }^{2}$ See Payments Canada for detailed information about Canada's payments modernization program: https://modernization.payments.ca/?_ga=2.37363368.905859778. 1594361561-1612010217.1574459451 As part of this, LVTS and ACSS will be replaced over the next years by three new systems: a real-time gross settlement (RTGS) system for large-value payments (Lynx), a deferred-net-settlement (DNS) batch system for less urgent lower-value payments (SOE), and a new system for real-time processing of small-value payments (RTR), along with newly developed RTR-based payment instruments (that enable consumers and businesses to initiate payments that are processed in the RTR) for consumers and businesses.
} 
To better understand these potential risks and how to best address them, the aim of this paper is to predict the future use of Lynx, SOE and RTR by end-users (consumers and businesses) and financial institutions. We employ historical LVTS and ACSS data and use the discrete choice demand estimation approach to uncover end-users' and financial institutions' preferences when deciding which payment instruments and payment systems, respectively, to use. This approach is based on the idea of "revealed preferences," meaning that the actual decisions made by agents reveal their underlying preferences. Based on the estimated revealed preferences, we conduct various counterfactual analyses to estimate the volume and value shares of the future payment systems.

Overall, our results suggest that without additional regulatory restrictions: (i) Lynx will inherit at least $50 \%$ of the large-value, inter-bank payments currently processed in LVTS; (ii) SOE will attract almost $50 \%$ of the small-value, client-driven LVTS payments; and (iii) RTR and RTR-based payment instruments will take on a non-negligible fraction of payments, both from ACSS (around 6\%) and LVTS (almost $20 \%)$.

Our findings are in line with those presented in our companion paper Kosse et al. (2020). In that paper, we provide a high-level indication of the potential migration patterns based on a qualitative analysis of the attributes of the existing and future payment instruments and payment systems in Canada. $3^{3}$ In the current paper, we take a more quantitative approach based on a model of demand for payment instruments/systems and actual historical payments data. Also, our study is related to Dingle (2003), who provides an earlier account of the development of ACSS and LVTS and how policy makers monitored and controlled (to a certain extent) the migration

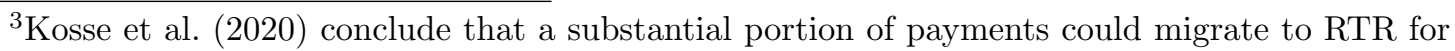
more convenience, speed and functionality. Also, they argue that large LVTS transactions could migrate to RTR or SOE.
} 
of payment flows between the two systems.

Our conclusions contribute to the current policy discussions about the design of Lynx, SOE and RTR. The estimated migration of large-value LVTS transactions to SOE and RTR might require additional risk measures to mitigite increased credit risk exposure or fraud risks. The results of our scenario analyses demonstrate that the migration of LVTS payments into SOE and RTR will be very limited in case of an RTR value limit of CAD 22,000 and an SOE limit of CAD 25 million.

The remainder of the paper is structured as follows: Section 2 provides background information on the current Canadian payment modernization initiative and explains how the expected payment migration will driven by agents' decisions. Section 3 describes the historical payments data that we use, and Section 4 discusses the framework that we apply to this data to model the current payment choices of Canadian end-users and financial institutions. The results of this model are presented in Section 5, while Section 6 discusses the outcomes of the counterfactual simulations that predict the payment migration patterns once the new Canadian payment systems have been introduced. Section 7 concludes.

\section{Payments Modernization and Migration}

\subsection{Payment Modernization in Canada}

Payments Canada, the owner and operator of Canada's core payment systems, is undertaking a large initiative to modernize the Canadian payments ecosystem. The goal is to achieve a modern payments landscape that is fast, flexible and secure;

promotes innovation; and strengthens Canada's competitive position ${ }^{4}$ As part of this

\footnotetext{
${ }^{4}$ See Payments Canada (2016)
} 
initiative, Payments Canada will offer three core payment systems that complement one another by each serving a different purpose: a RTGS system for large-value payments (Lynx), a DNS batch system for less urgent lower-value payments (SOE), and a system for real-time processing of small-value payments (RTR). Lynx, SOE and RTR will replace the current Canadian core payment systems: the LVTS for large-value and time-critical payments, and the ACSS for lower-value and less urgent retail payments. Although ACSS and LVTS still function and are regularly being upgraded, they were built more than 20 years ago. As a result, it is increasingly challenging to keep them equipped with the latest technologies and risk controls, and to fulfill the rapidly growing demand for faster, safe and information-rich payments.

The current and future systems differ from each other in a variety of aspects. We briefly summarize these differences below and in Figure 1. For a more detailed summary of the attributes of the systems, see Table 2 of Kosse et al. (2020).

- SOE will have many of the same characteristics as the current batch system ACSS, with the exception of having end-of-day instead of next-day settlement. Also, SOE aims to have less restrictive access criteria than ACSS, meaning that a larger number of financial institutions are able to use the system. As currently foreseen, $\mathrm{SOE}$ will be able to process the same batch payment instruments that are currently processed in ACSS.

- LVTS is an equivalent to an RTGS system, as payments are processed with finality while netted and settled end-of-day ${ }^{5}$ Lynx, by contrast, will truly allow for real-time settlement. Lynx also differs from LVTS in that every payment sent through Lynx will need to be fully backed with liquidity, such that any default is fully covered.

\footnotetext{
${ }^{5}$ See Arjani and McVanel (2006) for a detailed description of the LVTS system.
} 
- Today, LVTS offers two mechanisms that banks can choose between when submitting a payment: LVTS Tranche 1 (T1) and LVTS Tranche 2 (T2). Lynx, too, will offer two distinct mechanisms: Lynx LSM and Lynx UPM. Lynx's Liquidity Savings Mechanism (LSM) will enable banks to reduce the amount of liquidity required to settlement payments as it uses a combination of queuing, intraday liquidity recycling, and payment offsetting. For payments that must be settled immediately, participants may use Lynx's Urgent Payment Mechanism (UPM), where payments will not be delayed or offset.

- RTR will be a new capability for smaller-value payments. It is aimed to foster the availability of new payment instruments that enable end-users to make payments in real-time. Although RTR will have the same funds availability and liquidity requirements as Lynx UPM, it will have a more open access regime and will not be able to process international (i.e., correspondent banking) transactions.

- All three future systems will use the international ISO 20022 standard for messaging. This will allow for higher interoperability across systems, both nationally and internationally.

\subsection{Payment Migration}

The migration of current ACSS and LVTS payments to the future systems will be the outcome of an interaction between financial institutions and end-users (i.e., consumers and businesses). Financial institutions will decide which system(s) to join and which payment instruments to offer 6 At the same time, end-users will decide which bank

\footnotetext{
${ }^{6}$ By doing so, financial institutions can influence their clients' decisions through pricing or other features, such as ease of use (i.e., the ability to pay via online banking). Financial institutions' decisions like these will be a function of various factors, such as the costs of the systems, client
} 
to bank with and which payment instruments to use.

It is challenging, from both modelling and data perspectives, to fully account for the joint decision of which payment instrument/system to use..$^{7}$ However, we can proceed with the "divide-and-conquer" idea and focus on specific use cases, where reasonable assumptions can be made to simplify the decision problem. For example, payment instrument choice can be assumed to be mainly driven by the end-users' preferences, because payment instruments offered by different financial institutions are rather homogeneous due to competition pressure. On the other hand, when a payment request is sent by end-users to financial institutions, the decision of which payment system to use for its settlement is mostly up to the financial institutions' cost-benefit considerations.

Specifically, regarding the payment migration question, since SOE and Lynx are the replacement systems for ACSS and LVTS, it is natural to assume that all banks that currently offer ACSS- and LVTS-based payment instruments will join SOE and Lynx and therefore keep offering the same sets of instruments. Moreover, in this paper we assume that all these banks will also join RTR and start offering RTR-based payment instruments. Although banks will have to incur a cost for connecting to an additional third system, they are likely to do so because of market competition pressure. In the past, end-user demand has played an important role in banks' decisions about which payment instruments to offer, so banks may run the risk of losing their clients when not also moving to RTR.

Hence, the final distribution of the payment flows processed in Lynx, SOE and RTR will be strongly driven by end-users' uptake of RTR-based instruments, as well demand and competition pressures.

${ }^{7}$ Specifically, we would need to model the strategic interactions of decisions made by payor, payee as well as their financial institutions, see, among others, Huynh et al. (2019) along this line of research. Also, estimating such a model would require detailed information on all the decision makers' actions. Unfortunately, we do not have such data in hand. 
as by banks' discretion in how to process their clients' and their own payments. When end-users make a payment using their instrument of choice, their banks will execute these through the appropriate systems, e.g., RTR-based payments will by default be submitted to RTR, and the SOE-based instruments will have to be processed through SOE. However, when end-users make a wire payment, banks can technically send these to either system. It is reasonable to assume that this decision is heavily driven by banks' preferences: clients do not really care which system is used, as long as their payment needs, e.g., expected speed, are satisfied. The same is true for the banks' own transactions - given that all three future systems will be based on the same ISO messaging standard, we assume that these could potentially be processed through Lynx, SOE or RTR.

Based on this, our following analyses are structured around the following two specific migration questions:

- What is the value share of ACSS and LVTS payments that will migrate to RTR due to end-user preferences?

- What will be the future market shares (both in volume and volume) of Lynx, RTR and SOE for the processing of "current" LVTS payments if it were up to financial institutions to decide?

\section{Data Overview}

\subsection{Data Source}

In order to model current payment choices in Canada and to predict what these choices will look like once the new core payment systems have been launched, we employ historical transaction data collected from the two present core payments systems 


\section{LVTS and ACSS.}

The LVTS dataset that we use contains information about each single payment that direct participants (hereafter referred to as financial institutions) processed through LVTS from 2004 to 2018. For each payment, we know which of the two LVTS tranches the payment was sent to: LVTS Tranche 1 (T1) or LVTS Tranche 2 (T2). From the perspective of financial institutions, an important difference between these two tranches is their liquidity costs. Using T1 is more costly for banks than T2, since every payment needs to be fully collateralized in order to be processed (see also Kosse et al. (2020)). To process a payment through T2, however, financial institutions need to be granted bilateral credit limits (BCLs) by the receivers of their payments. If a payment exceeds these limits or the overall $\mathrm{T} 2$ net debit cap, the payment cannot be processed in $\mathrm{T} 2 \mathrm{~g}^{8}$

Payments made to the Bank of Canada (BoC) are mostly sent through T1 because of the small BCLs granted by the BoC. As this is limiting financial institutions' freedom of choice, we have excluded payments to the BoC from the data and analyses. We also exclude payments that are less than CAD 10 as these are mostly test payments.

Other transaction characteristics that we observe in the LVTS dataset include the name of both the sending and receiving financial institution, the value of the payment, the exact timing of the payment and a label indicating if the payment was inter-bank or client driven.

The ACSS data contains the monthly bilateral payment values and volumes sent through ACSS between 2004 and 2018 among the different pairs of financial institutions. This data is further broken down by payment instrument that was used by

\footnotetext{
${ }^{8}$ For more information about LVTS and its two tranches, see Arjani and McVanel (2006).
} 
the end-user to initiate the payments (ABM withdrawal $]^{9}$ AFT credit, AFT debit, cheques, EDI, debit card, and online or paper bill payment).

In order to capture the use of payment instruments that are currently processed outside of ACSS and LVTS, we complement the above data with Interac e-Transfer statistics. Interac e-Transfer is a domestic payment instrument that allows end-users to send and receive electronic person-to-person payments in near real-time. The Interac e-Transfer data (i.e., transaction volumes and values) are only available at an annual level.

\subsection{Descriptive Analysis}

Now let us take a first look at the data. We shall first describe the trend of market shares of ACSS- and LVTS-based payment instruments over the past years and then summarize the market shares of LVTS-T1 and LVTS-T2 payments in the LVTS system.

\subsubsection{Use of Payment Instruments by End-users}

Figure 2 show the yearly transaction values and volumes of the main payment instruments used by Canadian end-users between 2004 and 2018.10 The value and volume of "Wire" are calculated using the client-driven payments in LVTS; the data for the other instruments are taken from the ACSS system. The most obvious pattern is that the relative share of electronic instruments, such as AFT, EDI and wire transfers, has increased over the years at the expense of paper-based instruments, such as cheques

\footnotetext{
${ }^{9}$ Unfortunately, we do not have individual cash transaction data. The ACSS data however contains ABM cash withdrawal data, which we will be working with in this paper as an indicator of end-users' demand for cash.

${ }^{10}$ Given the confidential nature of our Interac e-Transfer data, this instrument is excluded from the figures.
} 
and cash (reflected by ABM withdrawals). These historical trends are informative for anticipating the future payment values and volumes of each payment instrument.

Our data also allows us to identify how the use of the different payment instruments by end-users differs depending on the financial institution they are banking with. Figure 3 shows the value and volume shares of the different payment instruments used by the clients of the six largest banks in Canada (often referred to as the "Big 6") and those of the smaller banks (grouped as "Others") ${ }^{11}$ It shows that the use of cheques and debit cards, for instance, varies largely across banks. This observed heterogeneity suggests that the clients of these financial institutions have different preferences when it comes to payment instruments, which may result from different demographics or other factors. These variations among banks play an important role in the identification of the parameters of our demand model and will help improve the precision of our predictions.

\subsubsection{Use of Payment Systems by Financial Institutions}

The LVTS data allow us to study the preferences of financial institutions when it comes to choosing which payment system to use for their payments. Whenever financial institutions send a payment to LVTS, they can either send it through LVTS Tranche 1 (T1) or LVTS Tranche 2 (T2), which could be considered as two different systems. Therefore, the breakdown of the LVTS data by tranche enables us to determine the relative use of each of these tranches, and to identify the underlying drivers.

Since we observe the transaction value of each LVTS payment, we are able to study

\footnotetext{
${ }^{11}$ The Big 6 banks initiate and receive about $85 \%(87 \%)$ of the total value (volume) of all the payments in our ACSS and LVTS data. So lumping the smaller banks together can help us to get around the potential issue of sampling error related to the limited market share of some of these smaller banks.
} 
financial institutions' use of T1 and T2 for different transaction values. Moreover, given the large number of payments in our dataset, we aggregate all of them into groups defined by sender-receiver-tranche-value percentile combinations, where the value percentiles are simply 100 equal-volume bins defined by value.

Figure 5 shows, for each of these 100 value bins (on the vertical axis) and for different financial institutions (on the horizontal axis), what share of payments was sent through T1 and what share was processed through T2. It demonstrates that the large majority of payments in the small and medium value bins are sent through T2. The share of T1 payments, however, starts to increase as the transaction values get bigger. Also, the smaller banks grouped as "Other" tend to use T1 relatively more often than the Big 6 do. This suggests that the smaller banks face different trade-offs (e.g., liquidity costs, insufficient bilateral credit limit in T2) than the bigger banks when deciding which tranche to use. This heterogeneity by financial institutions and by transaction value will help identify our model and generate predictions at a rather granular level.

\section{An Empirical Model of Demand for Payment Instruments and Systems}

\subsection{Basic Framework}

Given an underlying economic transaction that requires a payment, choosing among payment instruments or systems is inherently a discrete choice problem $\left[{ }^{12}\right.$ Therefore

\footnotetext{
${ }^{12}$ Here we assume that a payment (characterized by its size and other attributes, e.g., timing) is exogenously given and we only model the conditional choice of alternative payment instruments/systems. We think this is a reasonable assumption in this context because a payment is derived from some underlying economic transaction that depends little on how the payment is settled eventually.
} 
we apply the standard discrete choice demand framework used in empirical Industrial Organisation (see, among others, Berry (1994) for details) to model end-users' choice of payment instrument and banks' choice of payment system. As we mentioned earlier in Section 2, we do not model the details of each agent's decision process and their potential interactions, but treat the payer, payee and their financial institutions collectively as one single entity and focus on their final joint decision on which instrument (for end-users) and which system (for banks) to use. We call this single entity (and the intended payment in question) a decision maker and label it $i$.

In our model, a market $t$ consists of a population of decision makers and a set of different payment instruments and systems (denoted by $\mathcal{J}_{t}$ ) that end-users and banks respectively can choose from. A payment instrument or system $j \in \mathcal{J}_{t}$ in market $t$, is associated with a vector of observed characteristics $X_{j, t}$ and an unobserved attribute $\xi_{j, t}$. Note that $X_{j, t}$ can include attributes of the instrument or system $j$ itself, as well as market $t$ specific characteristics. The unobservable component $\xi_{j, t}$ captures any unobservable shock that might impact the use of a payment instrument or a system, such as latent payment instrument or payment system attributes or macroeconomic shocks.

Given the choice set of available payment instruments and payment systems, a decision maker's optimal choice is determined by its preference. This preference is represented by a random payoff function 13 The payoff that decision maker $i$ obtains from choosing payment instrument or payment system $j$ in market $t$ can be defined

\footnotetext{
${ }^{13}$ This is effectively the Random Utility Model (see the groundbreaking work of McFadden (ed. by P. Zarembka, New York, Wiley, 1973)), but we use the word "payoff" instead of "utility" since our notion of decision maker goes beyond that of an individual consumer.
} 
as:

$$
\begin{aligned}
\pi_{i, j, t} & =\delta_{j, t}+\varepsilon_{i, j, t} \\
& =X_{j, t} \beta+\xi_{j, t}+\varepsilon_{i, j, t}
\end{aligned}
$$

where $\delta_{j, t}$ is the mean payoff that is common across all decision makers, $\beta$ is the parameter of interest that we want to estimate, and $\varepsilon_{i, j, t}$ is a preference shock following the standard type-I extreme value distribution (i.e., logit error). To normalize the level of the payoff function, we set the mean payoff of one option in the choice set $\mathcal{J}_{t}$, i.e. the "base" option, to zero such that $\delta_{0, t}=0$.

Each decision maker is assumed to choose the payment instrument or payment system that gives the highest payoff. The aggregation of individual choices yields the aggregate choice probability (i.e., the market share) of $j$ in $t$ as:

$$
s_{j, t}=\sigma_{j}\left(\delta_{t}\right)=\frac{\exp \left(\delta_{j, t}\right)}{1+\sum_{k=1}^{J_{t}} \exp \left(\delta_{k, t}\right)}, \forall j, t
$$

where $s_{j, t}$ is the observed market share ${ }^{14}$ and $\delta_{t}=\left(\delta_{1, t}, \ldots, \delta_{J_{t}, t}\right)$. The demand system (1) connects the observed outcome (i.e., the market shares of individual payment instruments and systems) and the underlying payoff function, and it forms the basis for the estimation of the unknown parameter $\beta$.

The logit model specified above is widely used because it is easy to estimate and has a clear behavioral foundation (see Luce (1959)). A drawback of the logit model is its well-known independence of irrelevant alternatives (IIA) property, which implies a rather restrictive substitution pattern among the options in the choice set: the

\footnotetext{
${ }^{14}$ Driven by the available data, we focus on value shares when estimating end-users' demand for payment instruments and on volume shares when modeling financial institution's demand for payment systems.
} 
relative choice probability of two options is independent of any other alternatives in the choice set. In a specific payment migration problem in which we want to predict the market share of a newly introduced payment instrument, the logit model will predict that payments migrate to the new instrument in proportion to the relative market shares of the existing instruments.

Despite the limitation of the logit model, we think it is suitable for our application due to the limited richness of our data. Estimating (or identifying) a richer model, such as a nested-logit or a random coefficient logit model, would require a richer dataset with more information about each single transaction, payer, payee or associated financial institution.

To estimate the demand model (1), we apply the well-known logit choice probability inversion formula from Berry (1994) to obtain:

$$
\log \left(\frac{s_{j, t}}{s_{0, t}}\right)=\delta_{j, t}=X_{j, t} \beta+\xi_{j, t}, \forall j, t
$$

and then impose the standard mean independence assumption:

$$
E\left[\xi_{j, t} \mid X_{j, t}\right]=0
$$

Assumption (3) requires $X_{j, t}$ to be "exogenous" in the sense that it does not depend on $\xi_{j, t}$. We shall discuss the validity of this assumption in the specific applications below 15

\footnotetext{
${ }^{15}$ Besides the conditional mean restriction (3), we need an independence (or weak dependence) assumption on the error term $\xi_{j, t}$ (across $j$ and $t$ ). Alternative dependence assumptions can lead to different inference results on the parameter estimates. We shall report robustness standard errors in the estimation to handle the potential dependence and heteroskedasticity among $\xi_{j, t}$ 's.
} 
Finally, combining (2) and (3), we get:

$$
E\left[\log \left(\frac{s_{j, t}}{s_{0, t}}\right)-X_{j, t} \beta \mid X_{j, t}\right]=0, \forall j, t
$$

which are the moment conditions for estimation. Since the model is linear, the estimation is effectively a linear regression of the log ratio of the market shares of each payment instrument or system on the instruments' and systems' characteristics and on the market $t$ specific characteristics.

\subsection{End-Users' Demand for Payment Instruments}

We first apply the above framework to study the decision of end-users of which payment instrument to use. An end-user can be a consumer or a business, who intends to send a payment to another end-user for the exchange of a good or service.

As shown in Section 3 , our data contain the total value and volume of payments made by clients (i.e., end-users) of each pair of financial institutions. Based on this available data, we define a market as a combination of "year - financial institution of the payor - financial institution of the payee."16

Each market has the same set of payment instruments to choose from. Our final objective is to estimate this model and to use it to predict the short-term migration of end-users' payments resulting from the introduction of RTR. Since the current Interac e-Transfer will be the first payment instrument to be processed in the RTR once launched, we consider its predicted demand as a proxy for future end-users' demand for RTR. Therefore, our model estimations are focused on the use of Interac e-Transfer and those instruments that have a potential to be substituted by RTR-

\footnotetext{
${ }^{16}$ We have also tried using monthly level data for the estimation and found that it gives virtually identical results (when controlling for monthly fixed effects). Hence, there is no additional gain in using more disaggregated data.
} 
based instruments once the RTR is in place. As a result, in each market $\mathcal{J}_{t}$, end-users are assumed to be able to choose among Interac e-Transfer, cash (which would require an $\mathrm{ABM}$ withdrawal), $\mathrm{AFT}^{17}$, cheques and wire transfers ${ }^{18}$ Unfortunately, we only have yearly aggregate value and volume data on the use of Interac e-Transfer, without a breakdown by financial institution. Therefore, we assume that the aggregate transaction values and volumes are evenly distributed to all pairs of financial institutions 19

We set wire transfer as the base option and normalize its mean payoff to zero. The covariate vector $X_{j, t}$ includes dummy variables indicating the financial institution of the payer, the financial institution of the payee, the payment instrument, and a linear year trend 20 To respect the heterogeneity among the payment instruments since the payoff trends are likely to differ across instruments, we allow for heterogeneous preference parameters by implementing the moment condition (4) separately for each payment instrument.

Note that for a fixed $j$, the assumption (3) requires that the sender-receiver-year level demand shock is mean-independent of the variables in $X_{j, t}$, which includes sender dummies, receiver dummies and year trend. This assumption might be questioned if certain variables were omitted from $X_{j, t}$ and lumped into $\xi_{j, t}$, e.g., an interaction

\footnotetext{
${ }^{17}$ In our model, AFT includes both AFT Credit and AFT Debit.

${ }^{18}$ Based on our current knowledge, the focus of the initial release of RTR will be on person-toperson payments. So we want to construct the choice set of instruments such that it only includes instruments that are substitutable to the initial release of RTR. Therefore, current debit card transactions, as well as EDI and online and paper bill payments, are unlikely to migrate to RTR in the short run; these payment instruments are excluded from our analysis.

${ }^{19}$ Alternative assumptions on the value and volume distributions among different financial institutions may generate dissimilar results. However, we expect these differences to be rather insignificant in the short run because of limited overall market share of Interac e-Transfer. On the other hand, we do acknowledge that this claim may not hold in the long run. Thus, more granular data are needed (this is also what we hope to obtain in future research) for us to make more precise predictions for a longer horizon.

${ }^{20}$ We have also tried nonlinear specifications, such as a quadratic trend, but find that they do not lead to a higher prediction performance.
} 
between the dummies of two banks; however, we tried some alternative specifications with richer sets of variables in $X_{j, t}$ and found that they had little impacts on our main results.

\subsection{Financial Institutions' Demand for Payment Systems}

Next, we apply the same basic framework to model the current financial institutions' choic ${ }^{21}$ between T1 and T2 when sending a payment through LVTS. The payment could be either on behalf of their clients or for themselves. Understanding their current choices will help us predict their choices between Lynx, SOE and RTR when these new systems are launched.

We use 2018 transaction data and define the market $\mathcal{J}_{t}$ as a combination of "the financial institution sending the payment (sending FI) - the financial institution receiving the payment (receiving FI) - the value bin."22 Since there are currently only two options to choose among in each market, i.e., $\mathrm{T} 1$ and $\mathrm{T} 2$, we use a binary choice logit model. We set T1 as the base option to normalize the payoff function. Finally, for the covariate vector $X_{j, t}$ we use dummy variables for each sending FI, receiving FI and value bin (the definition of the value bins does not vary across instruments or financial institutions). In this case, the mean independence assumption (3) rules out potentially omitted interaction terms between dummies of sending FI, receiving FI and value bin. We have tried including some interaction terms in the model and the results are virtually unchanged. Moreover, including too many interaction terms would lead to the over-fitting problem and thus undermine the model's ability to

\footnotetext{
${ }^{21}$ As discussed in Section 2 this choice in principle is still a joint decision of payer, payee and financial institutions, but is effectively dominated by financial institutions.

${ }^{22}$ We only use 2018 data here because other recently years, e.g., 2017, 2016, etc., are very similar to 2018 in terms of payment value distribution and thus do not provide much additional information. Also, our estimation results suggest that the estimates do not have a precision problem, so we think the potential gain of incorporating data from additional years would be rather limited.
} 
make predictions.

\section{$5 \quad$ Estimation Results}

\subsection{End-Users' Demand for Payment Instruments}

Table 1 presents the estimation results of the end-users' demand model, i.e., parameters in the end-users' mean payoff. Note that for Interac e-Transfer, the model does not include payor's and payee's financial institutions' fixed effects (FE) because of the above mentioned data limitations.

The positive intercepts and negative year dummies for $\mathrm{ABM}$ and cheques show that the mean payoff of using these two paper-based instruments is relatively high initially, but decreasing over time. By contrast, the relative mean payoff of using an electronic payment instrument (AFT or Interac e-Transfer) is shown to follow the opposite pattern, starting from a low value but increasing over time. This is in line with the general trends in payment instrument usage presented in Section 3. Note that the trend in payoff function should be interpreted as a "reduced-form" account of end-users' aggregate preference towards a payment instrument. For example, an increasing trend could indicate an actual utility improvement in convenience, speed functionality, etc., but could also mean a growing adoption rate and popularity (i.e., network effect) or other advancement.

We also examine the fit of the model by comparing the actual and model-predicted mean payoffs. Figure 4 shows the comparison for ABM, AFT and cheques (recall that the mean utility of wire is normalized to 0 ). We can see that the model, albeit being rather parsimonious, captures the time trend in relative market shares (see equation (2)) quite well. 
A vast amount of empirical research on payment behaviour demonstrates how endusers' payment choices are influenced by the attributes of payment instruments, such as speed, convenience, costs and safety (see for instance Kosse (2014) and references therein). Unfortunately, limited by the available data, we are not able to estimate the payoff contributions from all these attributes. This is because these attributes are invariant for each instrument, so estimating the contributions with acceptable statistical precision would require the number of distinct instruments to be much larger than the number of attributes. Since we only have a handful of instruments in our sample, such an estimation is not feasible with our data in hand. As a result, in our estimated model all time-invariant payment instrument attributes are absorbed in the instrument-specific intercept. Yet, this limitation does not preclude us from predicting future end-users' demand using the estimated trend (see Section 6).

\subsection{Financial Institutions' Demand for Payment Systems}

Figure 6] summarizes the results of the estimation of financial institutions' choice between T1 and T2 when using LVTS. Each graph depicts for each bank, the estimated difference between the mean payoff of using T2 and that of using the base option T1 (on the vertical axis) for each value bin (on the horizontal axis). We can draw a few conclusions from the graphs. First, the relative mean payoff of T2 compared with T1 decreases with the size of a payment. In other words, for small-value payments, financial institutions have a clear preference for T2, while for larger payments the mean payoff yielded from using T1 becomes comparable to that of using T2 as the estimated difference in payoffs reaches zero. Second, the comparative preference of T2 over T1 is rather heterogeneous across financial institutions. In particular, the smaller banks grouped as "Others" exhibit a substantially weaker revealed preference 
for T2 compared with the six larger banks.

Note again that from the financial institutions' point of view, a key difference between $\mathrm{T} 1$ and $\mathrm{T} 2$ is their liquidity costs, with $\mathrm{T} 1$ being more costly. So the observed preference for $\mathrm{T} 2$ is likely to be driven by this. However, as the size of a payment gets large, the liquidity costs seem to become less of a concern. Apparently, other factors gain more weight in the financial institutions' decisions of which system to use, such as the concerns for higher credit risk in $\mathrm{T} 2$ than $\mathrm{T} 1$, requirements from clients, etc. For larger payments, the risk concern, which is based on trust between banks and the willingness to share risk between each other, might be a barrier for banks to use $\mathrm{T} 2$ and force them to use T1 instead. As a result, the reason that smaller banks grouped as "Others" appear to have a weaker preference for T2 might be that they are "forced" by other banks (and clients) to use $\mathrm{T} 1 \stackrel{23}{23}^{2}$

\section{Counterfactual Analysis}

Using the estimates from the above demand models, in this section we conduct counterfactual simulations to predict the future demand for payment instruments and systems when the new modernized systems - Lynx, SOE and RTR - are introduced.

\subsection{Introducing RTR-based Instruments to End-Users}

First, we assess the following question: if RTR were introduced in 2019 (the year following the period used for our model estimations), what would be its market shares in the first two years? The answer to this question provides us with a rough baseline

\footnotetext{
${ }^{23}$ This means that our analysis based on "revealed preference" may not capture the true preferences but rather the restricted ones of small banks; however, as long as these restrictions continue to exist in the modernized systems (we think this is the case), our predictions based the restricted preferences are still reasonable and relevant.
} 
estimate of the short-run adoption of RTR-based payment instruments by end-users and of the growth of the RTR system.

Note that RTR itself is not a payment instrument that end-users can use, but a system for the processing of real-time small-value payments. The current Interac e-Transfer will be (one of) the first payment instrument(s) to be processed through RTR. Therefore, for our first simulation (i.e., the baseline scenario) we assume that the predicted payoff of RTR follows the same trend as the current payoff of Interac e-Transfer. Since we focus on the impact of the introduction of RTR, we also assume that the pay-offs of the other instruments remain the same ${ }^{24}$ Subsequently, we examine two scenarios where the future payoff of RTR has a $10 \%$ and $20 \%$ improvement over the current Interac e-Transfer. Such an improvement reflects an ecosystem in which new RTR-based payment instruments are introduced that offer end-users a $10 \%$ and $20 \%$ higher level of utility, for instance, by offering more convenience, more functionalities or a broader acceptance than the Interac e-Transfer ${ }^{25}$

Figure 7 summarizes the results of the three counterfactual simulations. Overall, the total value processed in RTR might reach CAD 300 billion after two years when the current trend of Interac e-Transfer continues. Its value may even double if it provides end-users with a $10 \%$ better user-experience, for example when it enables end-users not only to use it for person-to-person or bill payments (which is currently the case for Interac e-Transfer) but also for making payments in stores. Despite this large growth potential, the findings suggest that the predicted market share of RTR will remain relatively small compared with the other instruments studied, such as wire transfers and AFT ${ }^{26}$ Therefore, the overall impact of the introduction of RTR

\footnotetext{
${ }^{24}$ Especially in the first years this is likely to be the case, since SOE is expected to share most of the characteristics of the current ACSS.

${ }^{25} \mathrm{~A} 10 \%$ overall improvement is quite ambitious for a new payment instrument, especially for the initial years. Therefore, the $20 \%$ scenario is a bit extreme and only serves as a robustness check.

${ }^{26}$ This is mainly because of the higher average transaction values of wires and AFTs.
} 
on end-users' payment behaviour is expected to be limited, at least for the first couple of years. This is in line with observations in other countries, such as the UK, Sweden, China, Poland and Denmark, where the use of real-time payment instruments is still relatively small (see Kosse et al. (2020)).

Note that the above simulations only consider shares from the four other instruments studied. It does not capture any potential "market expansion," where RTR takes on transactions currently paid using other payment instruments not considered in our analysis, such as debit card or credit card payments, or where it even generates new payments. Therefore, these results should be considered as being a baseline estimate of the future transaction values processed in the RTR.

\subsection{Financial Institutions' Demand for the Future Payment Systems}

\subsubsection{Baseline Results}

Which of the future systems will financial institutions use for the processing of their current LVTS transactions? The estimation results presented in Section 5 allow us to answer this question as they reveal the relative mean payoffs faced by financial institutions for using T2 instead of T1. For each market defined as a combination of "the financial institution sending the payment (sending FI) - the financial institution receiving the payment (receiving FI) - the value bin," the relative mean costs (negative payoffs) of using T2 compared with $\mathrm{T} 1$ can be depicted on a scale such as displayed in Figure 8. On this scale, the mean costs of $\mathrm{T} 1$ are set to zero, as it was used as the base option for the normalization of the model. The costs of $\mathrm{T} 2$ are consequently denoted as $-L$ ( $L$ is positive).

To simulate the future market shares of the new systems Lynx, RTR and SOE 
for the processing of "current" LVTS payments, we need to make assumptions on their relative mean payoffs and position them on the same scale. Recall that the estimation results of financial institutions' choice between T1 and T2 suggest that the payoffs are mainly driven by liquidity costs. Therefore, we rank the mean payoffs of the new systems based on their expected liquidity costs. We also assume that the idiosyncratic preference shocks for the new systems still follow standard type-I extreme value distribution.

We acknowledge that assuming the payoff difference between T1 and T2 is solely driven by liquidity cost has a risk of oversimplification, because there are other considerations, e.g., risk and timeliness, when it comes to the choice of a system. However, given the data and information in hand, we cannot separately identify the contribution of these different factors to the overall payoff. So based on our judgement (as well as other experts' advice), we decide to proceed by focusing on the most prominent difference between T1 and T2: liquidity cost. The results should be interpreted with this assumption in mind 27

In our simulation, we also distinguish between Lynx UPM and Lynx LSM, since Lynx too will have two distinct mechanisms. Lynx's Liquidity Savings Mechanism (LSM) will enable banks to reduce the amount of liquidity required to settle payments as it uses a combination of queuing, intraday liquidity recycling, and payment offsetting. For payments that must be settled without delay, participants may use Lynx's Urgent Payment Mechanism (UPM) ${ }^{28}$

Based on the latest information on the systems' configurations, we assume that (1) SOE is cheaper than LVTS T1 and close to LVTS T2, (2) Lynx UPM is close

\footnotetext{
${ }^{27}$ A recent paper by Rivadeneyra and Zhang (2020) studies the trade-off between liquidity cost and timeliness (or delay) in LVTS system and we hope to incorporate their findings in our counterfactual simulation in future research.

${ }^{28}$ See Kosse et al. (2020) for further details about Lynx UPM and Lynx LSM.
} 
to LVTS T1 and they are both more expensive than Lynx LSM, and (3) RTR is the most expensive system ${ }^{29}$

Given the assumed ranking, we estimated alternative scenarios, each using different assumptions regarding the exact relative costs of the new system (see table in Figure 8). Note that these assumed costs depend on the estimated cost difference between T1 and T2, L, for each combination of "sending FI - receiving FI - value bin". This makes the assumption "adaptive." That is, for small-value payments where $L$ was shown to be large and mainly driven by liquidity costs, SOE is assumed to have a much higher payoff than the other systems and thus likely to acquire a large market share. By contrast, for the larger payments, for which $L$ was found to be small and where liquidity costs play a smaller role, the assumed costs of the new systems are close to each other. Thanks to the adaptive nature of these assumptions, our predictions rely less on the assumptions itself, but more on the patterns observed in the historical data.

For each scenario, we apply the assumed cost structure to every combination of "sending FI - receiving FI - value bin" to simulate the market shares of the three future systems, while making a distinction between Lynx UPM and Lynx LSM. The results of the aggregated value shares are presented in Figure 9. It shows that SOE and RTR, which are both designed for processing smaller-value payments, are predicted to take over about $50 \%$ of the transaction value currently processed in LVTS. Figure 9 also demonstrates that the predicted value shares are relatively robust across the three different scenarios. This is because financial institutions' choice of which system to use for the high-value payments is less affected by the relative liquidity costs. Therefore,

\footnotetext{
${ }^{29}$ Among the new systems, SOE is assumed to be the cheapest option as it settles payments on a deferred net basis, followed by Lynx LSM which allows for multilateral netting. Lynx UPM is taken to be the second most expensive system as it does not allow for payments to be netted. RTR is assumed to be the most expensive system, as it, as opposed to Lynx UPM, does not have a queuing mechanism just in case banks are temporarily short of liquidity.
} 
these high-value payments are likely to move from LVTS to Lynx-UPM or Lynx-LSM. Hence, Lynx will have a substantial volume share for these payments and thus have a rather large total value share ${ }^{30}$

The predicted migration pattern of LVTS payments to Lynx instead of SOE is in line with our expectations; however, the migration potential to SOE might still be overstated because our simulation does not take an important disadvantage of SOE into account: lack of timeliness. To see this, recall that SOE will be a deferred net settlement system, as a result of which a payment is not immediately final and receivers face a delay in receiving the funds. Such a delay could be a concern for large value payments (i.e., greater risk exposures), either based on the considerations of financial institutions themselves or their clients, and hence a driver for financial institutions to use Lynx instead.

\subsubsection{Additional Analyses}

To examine the simulation results at a more granular level, we first examine the simulated volumes for each of the value bins, see Figure 10, It shows how SOE is predicted to take on the vast majority of low-value LVTS payments because of its relatively low liquidity costs. However, for the largest transactions grouped in the highest value bins at the top of the graphs, both RTR and Lynx are predicted to have a substantial market share.

Secondly, we run an alternative set of scenarios that take into account the potential impact of value caps imposed to the future smaller-value systems SOE and RTR. Such value limits are quite common. For example, the current ACSS system only processes cheques with a value up to CAD 25 million. Similarly, at the time of writing, the

\footnotetext{
${ }^{30}$ Recall that in our analysis, we exclude the payments to and from the Bank of Canada. We expect these payments will migrate to Lynx "automatically," so the eventual value/volume share of Lynx tends to be greater than what we have predicted.
} 
faster payment system introduced in Europe by the European Payments Council only processes transactions up to EUR 15,000, which equals around CAD 22,000.

To get a sense of how similar value caps would affect the payments migration in Canada, we simulate the model while assuming a value cap of CAD 22,000 for RTR and a cap of CAD 25 million for SOE. In particular, for payments that exceed the cap of RTR (or SOE), we remove RTR (or SOE) from the choice set when simulating the market shares. The results are presented in Figure 11. The three scenarios again refer to the three different assumptions regarding the relative liquidity costs of the future systems. The results demonstrate that potential value caps for SOE and RTR will have a significant impact on the payments migration. In particular, the migration of payments out of the current LVTS into the new smaller-value systems SOE and RTR is predicted to be very limited in the case of an RTR cap of CAD 22,000 and an SOE cap of CAD 25 million. This also indicates that, although now blocked by the value caps, the pressure of financial institutions to migrate (part of) their LVTS payment into SOE or RTR is rather high 31

Finally, exploiting the information we have in our LVTS dataset that identifies whether the LVTS payment was made on behalf of a client or on the banks' own behalf, we re-run the above predictions for each of these payment types. Figures 12 and 13 present the results for the client-driven and bank-driven payments respectively. The graphs show that the value distribution is very different across both payment types: client-driven payments mostly fall in the smaller-value bins, while while bank-driven payments are mainly of a higher value. As a result, the expected volume that will migrate into SOE (i.e., the cheapest system) is shown to comprise many client-driven payments. This result is in line with our expectations, since our model showed how

\footnotetext{
${ }^{31}$ Note that this simulation does not take into account potential participants' strategic responses to the imposed value caps, such as splitting large payments into multiple smaller payments to circumvent the caps. Whether such responses are plausible, however, is an open question.
} 
financial institutions' system choices for smaller-value payments are mainly driven by liquidity costs.

\section{Concluding Remarks}

In this paper, we estimate a discrete choice model of demand for payment instruments and payment systems using Canadian payments data. Based on the estimated demand models, we run various counterfactual analyses to predict how payments will migrate from the current ACSS and LVTS systems into the new ones that are currently being developed by the Canadian payments industry.

Figure 14 and Figure 15 visualize the main results of our paper. First, they demonstrate that the future faster retail payment system RTR is likely to take on a fast-growing number of end-users' transactions in the short run. Yet, the overall share of RTR-based payments will likely remain limited in the first few years after its release. Second, our findings suggest that financial institutions have strong incentives to migrate a significant share of their LVTS payments to the future deferred-net-settlement system SOE designed for less urgent payments, because of the lower liquidity costs of SOE. In particular, smaller-value LVTS payments, which are often initiated on behalf of the financial institutions' clients, are likely to find their way into SOE. Also, we show that there is a potential that both small- and large-value LVTS payments will migrate to RTR if RTR is not subjected to maximum transaction values.

Combining the results on payment migration of both instruments and systems, driven by the demand of end-users and financial institutions respectively, we now have a complete (yet to be perfect) picture of the structure of Canada's future payment ecosystem: Without additional regulatory restrictions, (i) Lynx will inherit at least $50 \%$ of the large-value, inter-bank payments currently processed in LVTS; (ii) SOE 
will attract almost 50\% of the small-value, client-driven LVTS payments; and (iii) RTR and RTR-based payment instruments will take on a non-negligible fraction of payments, both from ACSS (around 6\%) and LVTS (almost 20\%).

Our analyses shed light on the incentives that end-users and financial institutions are facing when choosing a payment instrument and payments system to make and process a payment. The results also demonstrate the importance of these incentives in the expected payment migration patterns and formation of the future payments landscape. These migration patterns have important implications for payment system risks as well as social welfare. For example, a migration of large LVTS payments into SOE could lead to large end-of-day credit exposures, since SOE is based on end-of-day instead of real-time settlement. Similarly, a migration of large LVTS payments into RTR could lead to higher fraud risks, since RTR might have less stringent cyber security controls and more vulnerable points due to the more open access regime. These payment system risks could eventually affect overall financial stability. Therefore, the next step is to further understand these implications as well as the impact of potential risk mitigation measures, such as value caps and higher collateral requirements. 


\section{References}

Arjani, Neville and Darcey McVanel, "A primer on Canada's large value transfer system," Technical Report, Bank of Canada 2006.

Berry, S.T., "Estimating discrete-choice models of product differentiation," The RAND Journal of Economics, 1994, pp. 242-262.

Dingle, J., "Planning an evolution: the story of the Canadian Payments Association, 1980-2002," Technical Report, Bank of Canada and Canadian Payments Association 2003.

Huynh, Kim, Gradon Nicholls, and Oleksandr Shcherbakov, "Explaining the interplay between merchant acceptance and consumer adoption in two-sided markets for payment methods," Technical Report, Bank of Canada 2019.

Kosse, Anneke, "Consumer payment choices: room for further digitisation?," PhD Thesis, Tilburg University, School of Economics and Management 2014.

_, Zhentong Lu, and Gabriel Xerri, "An economic perspective on payments migration," Technical Report, Bank of Canada 2020.

Luce, R. Duncan, Individual choice behavior: a theoretical analysis, New York, NY, USA: Wiley, 1959.

McFadden, Daniel, "Conditional logit analysis of qualitative choice behavior," Frontiers in Econometrics, ed. by P. Zarembka, New York, Wiley, 1973, pp. 105-42.

Payments Canada, "Developing a vision for the Canadian payment ecosystem," Technical Report, Payments Canada, White Paper 2016.

Rivadeneyra, Francisco and Nellie Zhang, "Liquidity usage and payment delay estimates of the new Canadian high value payments system," Technical Report, Bank of Canada 2020. 


\section{Tables}

Table 1: Estimation Results: End-Users' Payoff Function

\begin{tabular}{ccccc}
\hline & ABM & AFT & Cheque & Interac e-Transfer \\
\hline \hline Intercept & $184.80^{*}$ & $-98.75^{*}$ & $200.93^{*}$ & $-689.71^{*}$ \\
& $(11.73)$ & $(6.43)$ & $(9.18)$ & $(8.73)$ \\
Year & $-.0984^{*}$ & $.0452^{*}$ & $-.1031^{*}$ & $.3378^{*}$ \\
& $(.0058)$ & $(.0032)$ & $(.0046)$ & $(.0043)$ \\
\hline Sending FI FE & Yes & Yes & Yes & No \\
Receiving FI FE & Yes & Yes & Yes & No \\
\hline Adjusted $R^{2}$ & .76 & .83 & .64 & .99 \\
\hline No. of Obs. & 645 & 645 & 645 & 15 \\
\hline
\end{tabular}

Notes: This table depicts the multinomial logit estimation results of the end-users' payoff function. Results should be interpreted relative to the base option Wires. Due to data limitations, the model for Interac e-Transfer does not include fixed effects for payor's and payee's financial institutions, i.e., the "Sending FI FE" and "Receiving FI FE" respectively. Robust standard errors are in parantheses, ${ }^{*} p<0.01$. 


\section{Figures}

Figure 1: Summary of payments modernization initiative

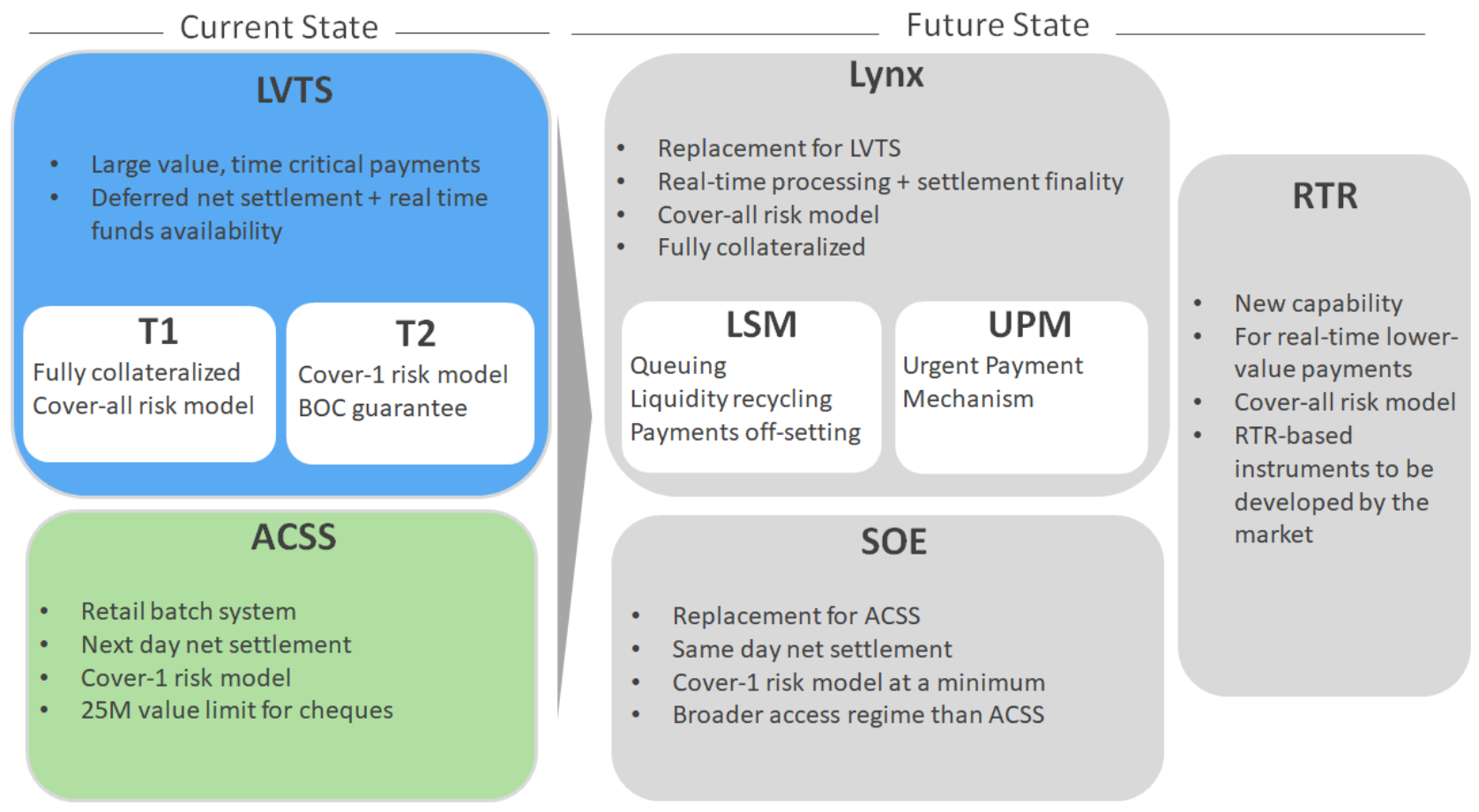

Notes: See Kosse et al. (2020) for more details. 
Figure 2: End-user's payment instrument choice: value and volume trend

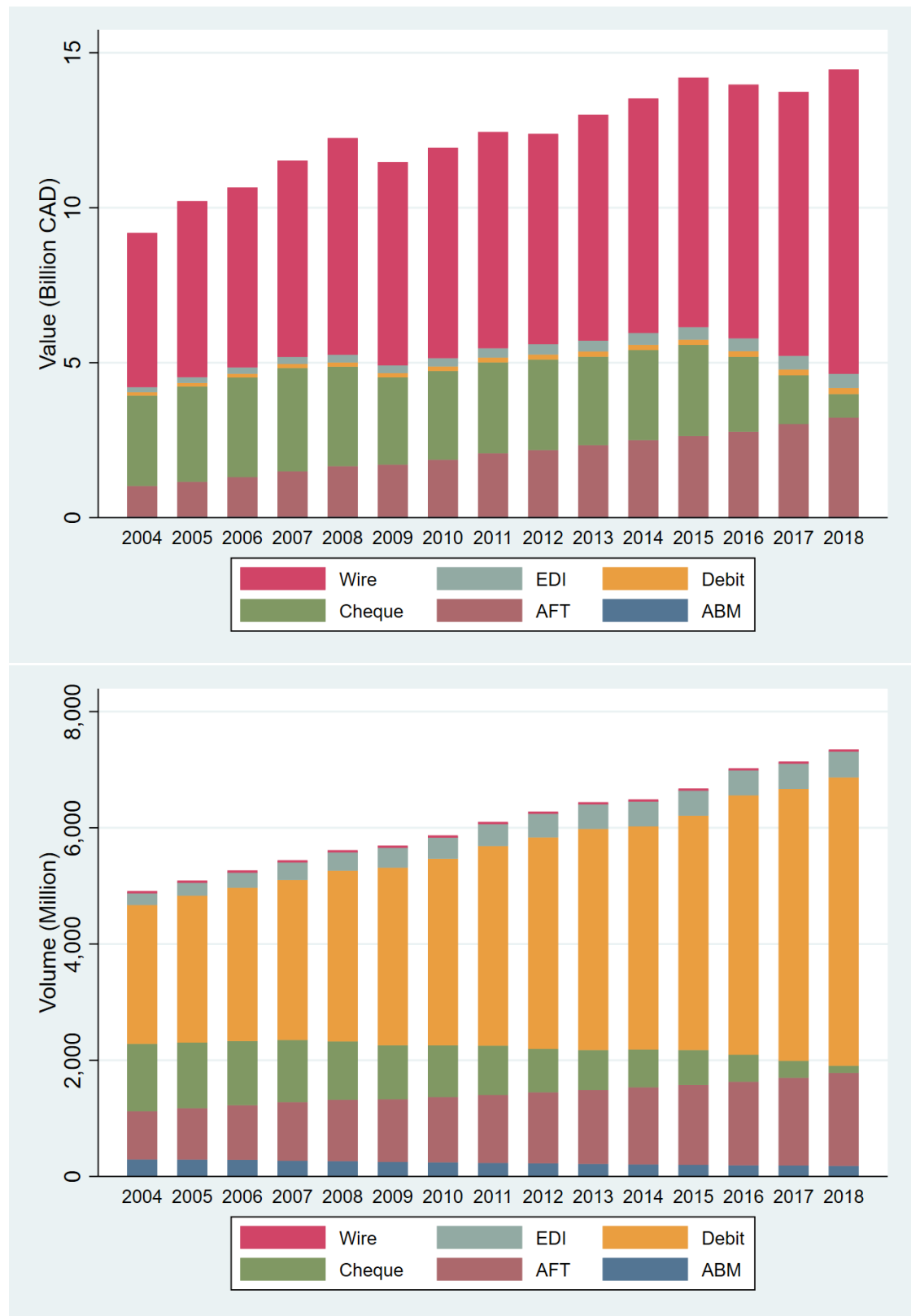

Notes: The above graphs show the annual values (in CAD billion) and volumes (in million) of the main payment instruments used in Canada. Sources: ACSS, LVTS. ABM = ABM cash withdrawals; $\mathrm{EDI}=\mathrm{EDI}$ payments and online and paper-based bill payments; Debit $=$ debit card; Wire $=$ clientdriven wire transfers processed in LVTS. See Kosse et al. (2020) for more details about instruments. 
Figure 3: End-user's payment instrument choice: heterogeneity across financial Institutions

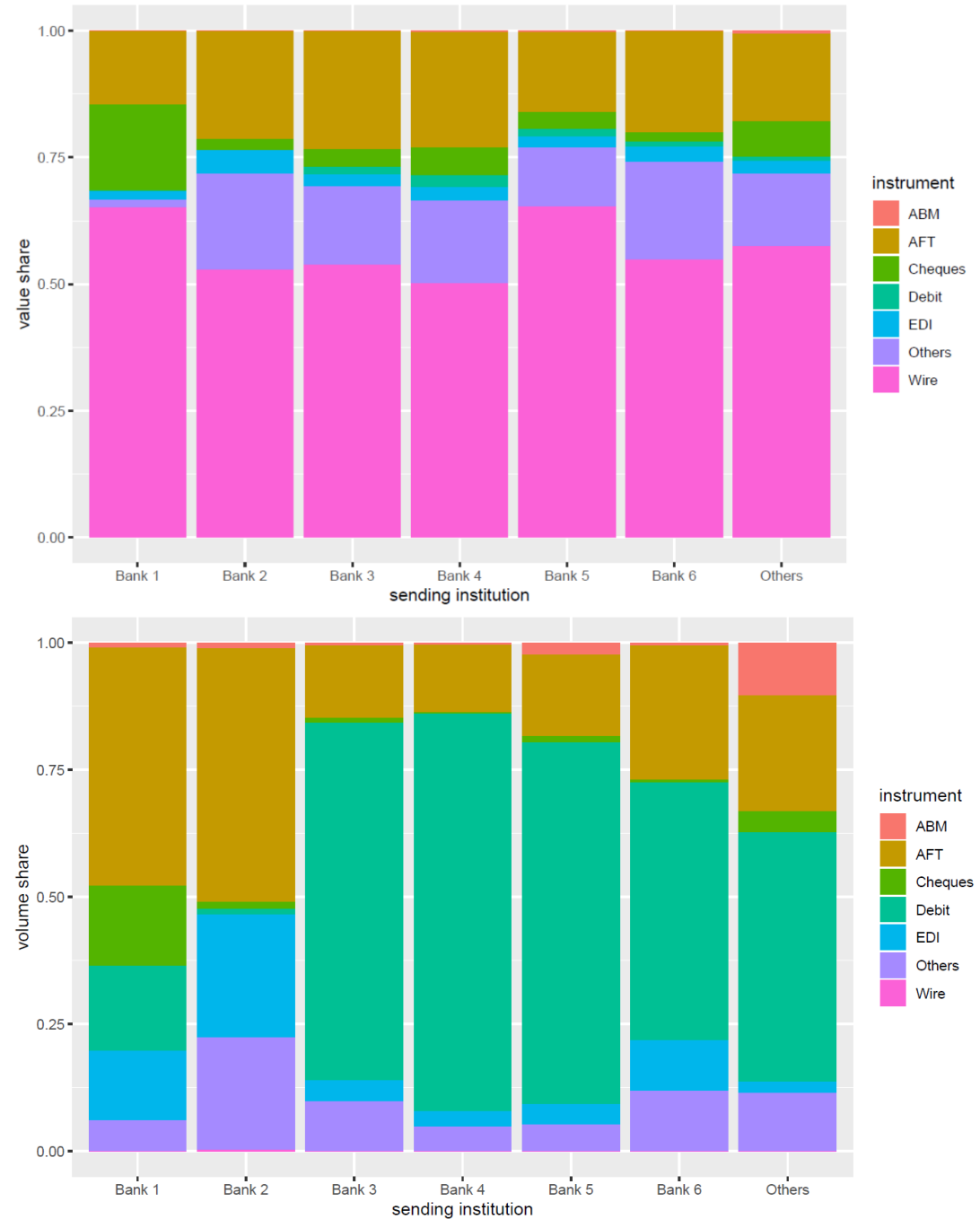

Notes: The above graphs show the average value shares (left) and volume shares (right) of the payment instruments processed in ACSS (ABM, AFT, Cheques, Debit, EDI, Others) and LVTS (Wire) between 2014 and 2018, broken down by financial institution of the clients initiating these payments. Bank 1 - Bank 6 represent the largest six banks in Canada. The remaining banks are grouped as "Others." Sources: ACSS and LVTS. ABM = ABM cash withdrawals; AFT = AFT Credit and AFT Debit; Cheques = cheques; Debit = debit card; EDI = EDI payments; Others = other ACSS-based payment instruments, including paper and online bill payments; Wire $=$ clientdriven wire transfers processed in LVTS. See Kosse et al. (2020) for more details about instruments. 
Figure 4: Model fit: observed versus fitted mean payoffs

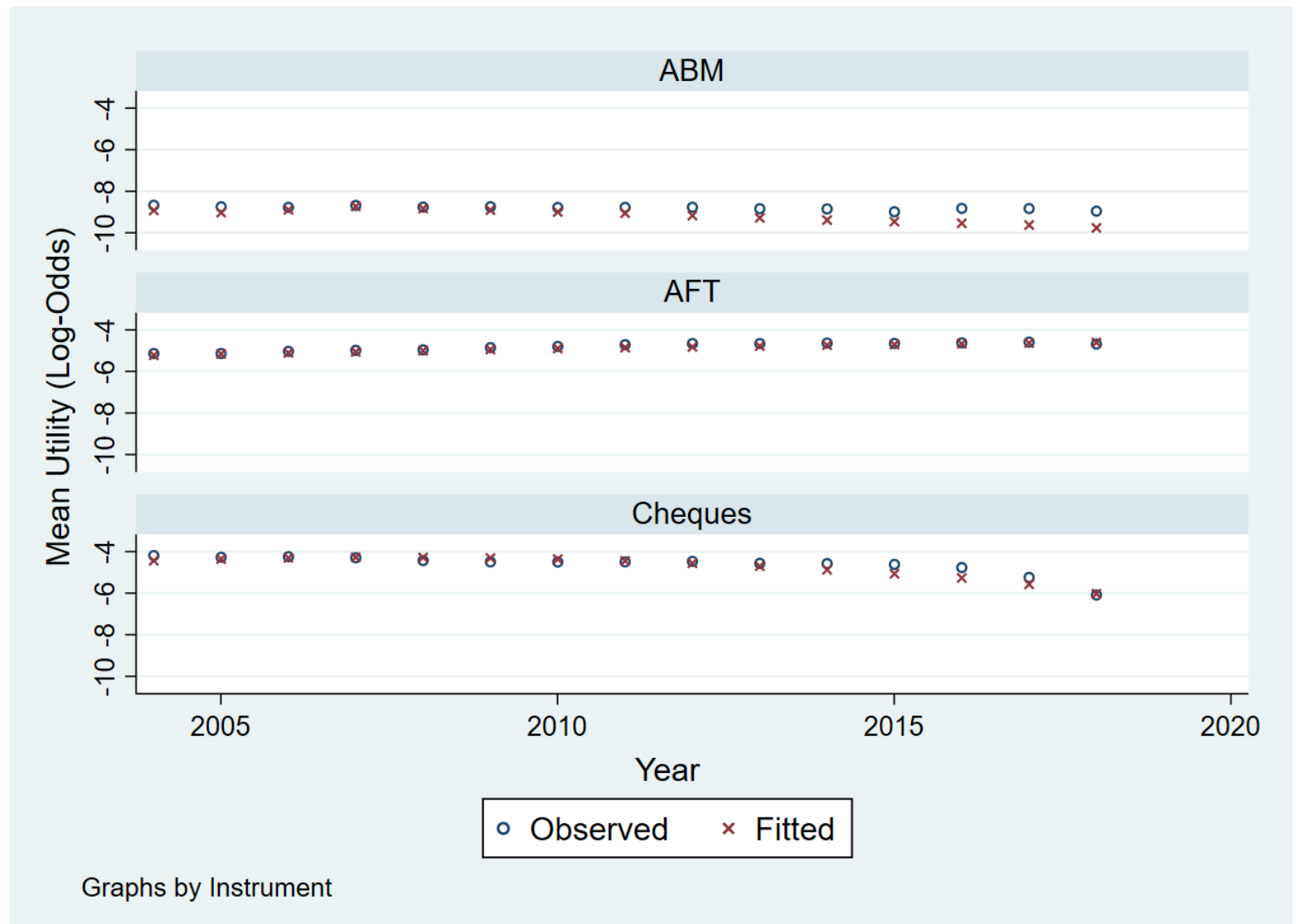

Notes: This graph shows the average "mean payoffs ( $\delta$ 's)" (across sending and receiving participants) for different years, as well as their fitted values based on the estimated end-user demand model in Table 1 . 
Figure 5: Volume shares of T1/T2: "Big 6" versus small banks

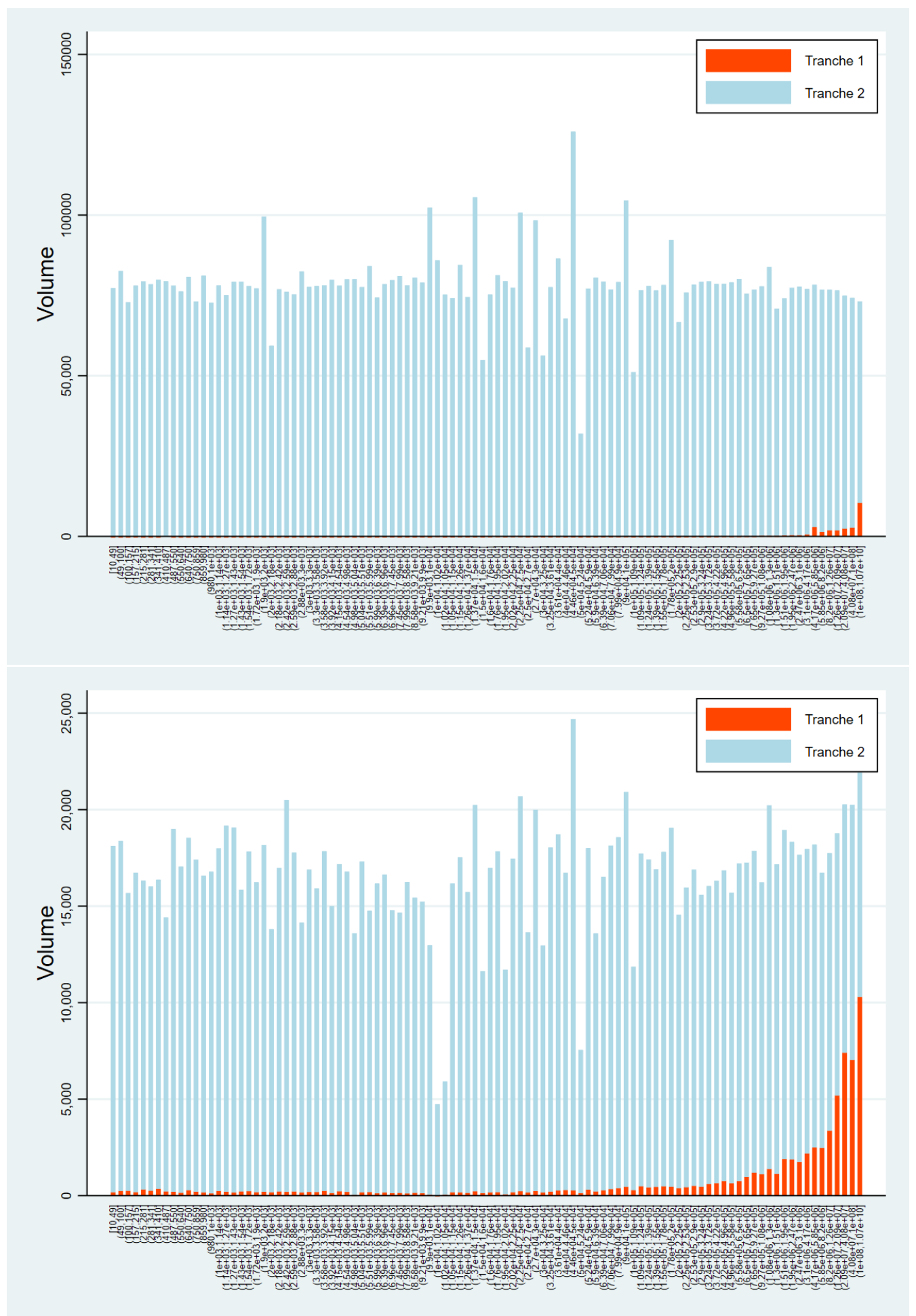

Notes: The above graphs show the volume shares of LVTS Tranche 1 (T1) and LVTS Tranche 2 (T2) for each of the value percentiles (left axis) and for the "Big 6" (upper graph, the 6 largest banks in Canada) and "Others" (lower graph, the remaining participants). Source: LVTS data. 
Figure 6: Estimation results: financial institutions' payoff function

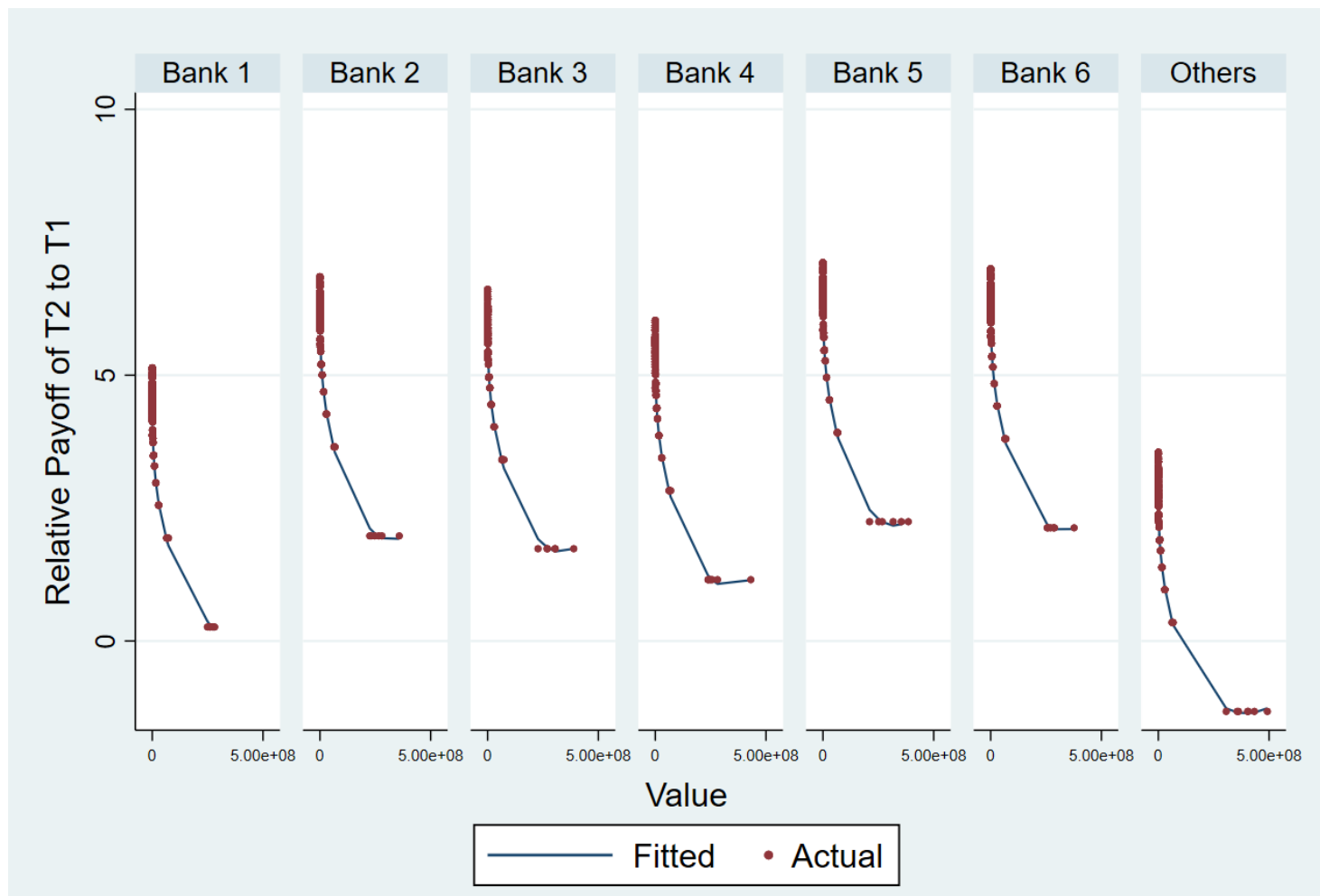

Graphs by Sending_FI

Notes: This graph depicts the binary logit results of the estimated difference between financial institutions' mean payoff of using LVTS Tranche 2 (T2) and their payoff of using LVTS Tranche 1 (T1) (on vertical axis) for different transaction values (on horizontal axis). The points labeled "Actual" are the estimated mean payoffs and the line labeled "Fitted" provides a fitted curve connecting the points to show the overall pattern. Bank 1 - Bank 6 represent the largest six banks in Canada. The remaining banks are grouped as "Others." This graph only shows the relative mean payoffs of the financial institutions sending the payments. Results are similar when depicting the results by receiving institution. 
Figure 7: Simulated value and shares: introduction of RTR

\begin{tabular}{|c|c|c|c|c|c|c|c|}
\hline Scenario & Year & Variable & ABM & AFT & Cheque & Wire & RTR \\
\hline \multirow{4}{*}{ Baseline } & 1st & Value (Billion \$) & 13.92 & $3,660.58$ & 798.81 & $9,626.32$ & 200.37 \\
\hline & & Market Share & $0.10 \%$ & $25.60 \%$ & $5.59 \%$ & $67.32 \%$ & $1.40 \%$ \\
\hline & $2 n d$ & Value (Billion \$) & 12.86 & $3,904.27$ & 583.36 & $9,813.16$ & 286.35 \\
\hline & & Market Share & $0.09 \%$ & $26.74 \%$ & $4.00 \%$ & $67.21 \%$ & $1.96 \%$ \\
\hline \multirow{4}{*}{$\begin{array}{c}10 \% \\
\text { Improvement }\end{array}$} & 1st & Value (Billion \$) & 13.70 & $3,602.76$ & 786.19 & $9,474.27$ & 423.09 \\
\hline & & Market Share & $0.10 \%$ & $25.19 \%$ & $5.50 \%$ & $66.25 \%$ & $2.96 \%$ \\
\hline & $2 n d$ & Value (Billion \$) & 12.60 & $3,823.71$ & 571.32 & $9,610.69$ & 581.68 \\
\hline & & Market Share & $0.09 \%$ & $26.19 \%$ & $3.91 \%$ & $65.83 \%$ & $3.98 \%$ \\
\hline \multirow{4}{*}{$\begin{array}{c}20 \% \\
\text { Improvement }\end{array}$} & 1st & Value (Billion \$) & 13.25 & 3484.67 & 760.42 & 9163.72 & 877.94 \\
\hline & & Market Share & $0.09 \%$ & $24.37 \%$ & $5.32 \%$ & $64.08 \%$ & $6.14 \%$ \\
\hline & 2 nd & Value (Billion \$) & 12.08 & 3666.79 & 547.88 & 9216.28 & 1156.97 \\
\hline & & Market Share & $0.08 \%$ & $25.12 \%$ & $3.75 \%$ & $63.13 \%$ & $7.92 \%$ \\
\hline
\end{tabular}

Notes: This table summarizes the predicted transaction value and value shares of ABM withdrawals, AFT debit and AFT credit (AFT), cheques, wire transfers and RTR. The predictions are based on the estimation results presented in Table 1 and data from 2004 to 2018. The "Baseline" scenario is an extrapolation of the historical trends with RTR following the same trend as the current Interac eTransfer. The "10\% Improvement" and "20\% Improvement" scenarios simulate the future assuming that the future payoff of RTR will be $10 \%$ and $20 \%$ higher than that of the current Interac e-Transfer. 
Figure 8: Counterfactual design of predicting migration to future payment systems

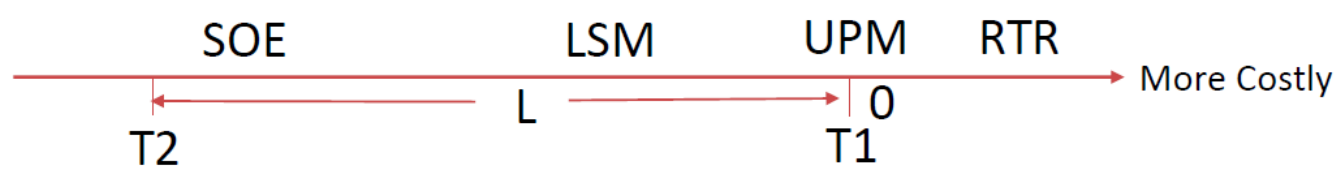

\begin{tabular}{|c|c|c|c|c|}
\hline & SOE & Lynx-LSM & Lynx-UPM & RTR \\
\hline Scenario 1 & $-65 \% * \mathrm{~L}$ & $-5 \% * \mathrm{~L}$ & $0 \% * \mathrm{~L}$ & $5 \% * \mathrm{~L}$ \\
\hline Scenario 2 & $-85 \% * \mathrm{~L}$ & $0 \% * \mathrm{~L}$ & $5 \% * \mathrm{~L}$ & $10 \% * \mathrm{~L}$ \\
\hline Scenario 3 & $-45 \% * \mathrm{~L}$ & $-10 \% * \mathrm{~L}$ & $-5 \% * \mathrm{~L}$ & $0 \% * \mathrm{~L}$ \\
\hline
\end{tabular}

Notes: This table summarizes the assumptions used regarding the expected (negative) payoffs of the future payment systems, as measured relative to the payoff difference between LVTS T1 and LVTS T2 $L$ estimated in Figure6 6. The assumptions for each of the three scenarios are based on the expected relative liquidity costs as depicted on the line above the table. T2 $=$ LVTS Tranche 2 , T1 $=$ LVTS Tranche 1, LSM = Lynx LSM, and UPM = Lynx UPM.

Figure 9: Simulated value shares of the future payment systems RTR, SOE and Lynx

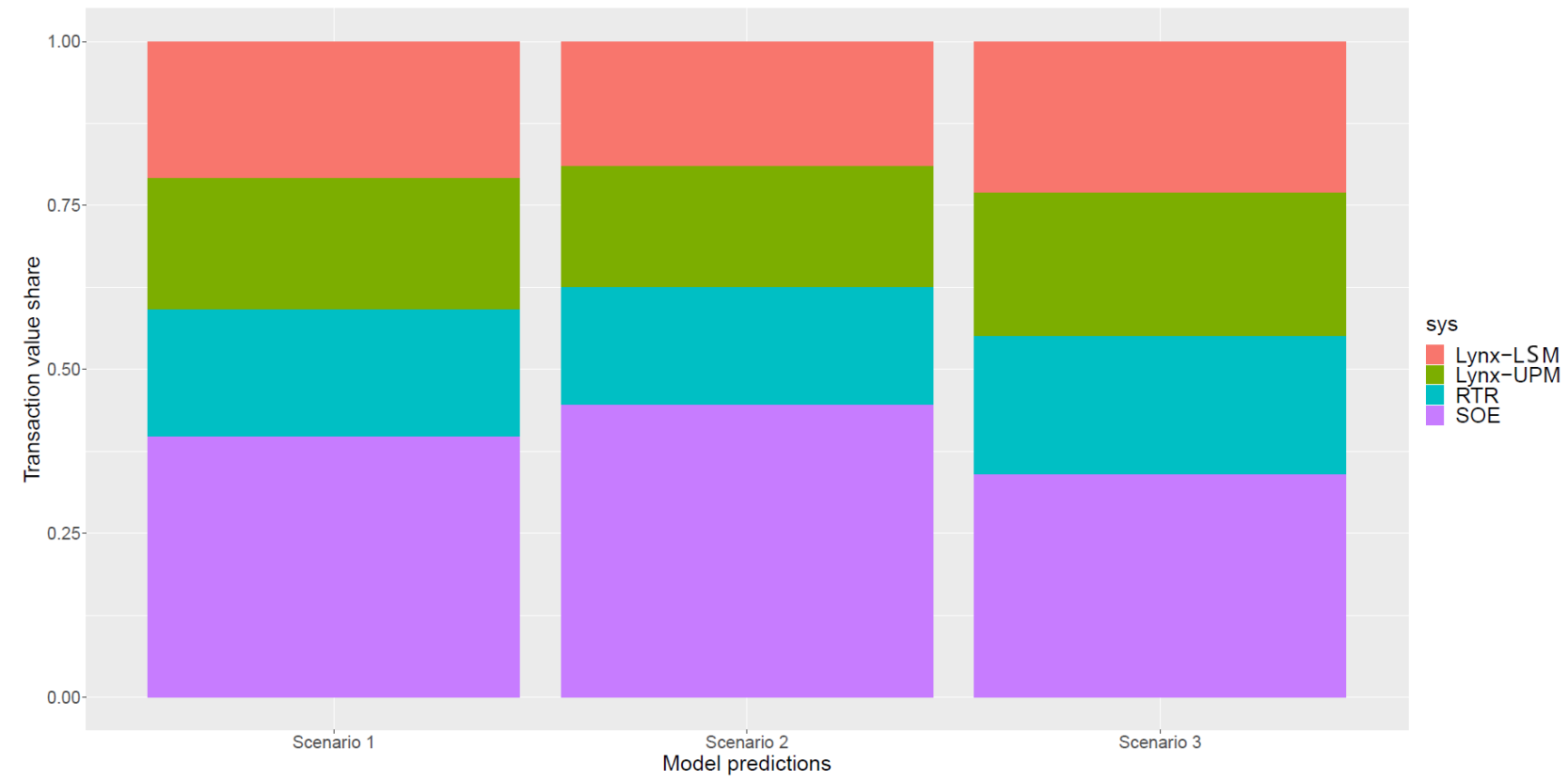

Notes: This graph summarizes the simulated value shares of the future payment systems Lynx (broken down by its two distinct mechanisms Lynx LSM and Lynx UPM), SOE and RTR, using the estimates generated by the binary logit estimation and the scenario assumptions listed in Table 8 
Figure 10: Simulated payment volumes in the future payment systems RTR, SOE and Lynx
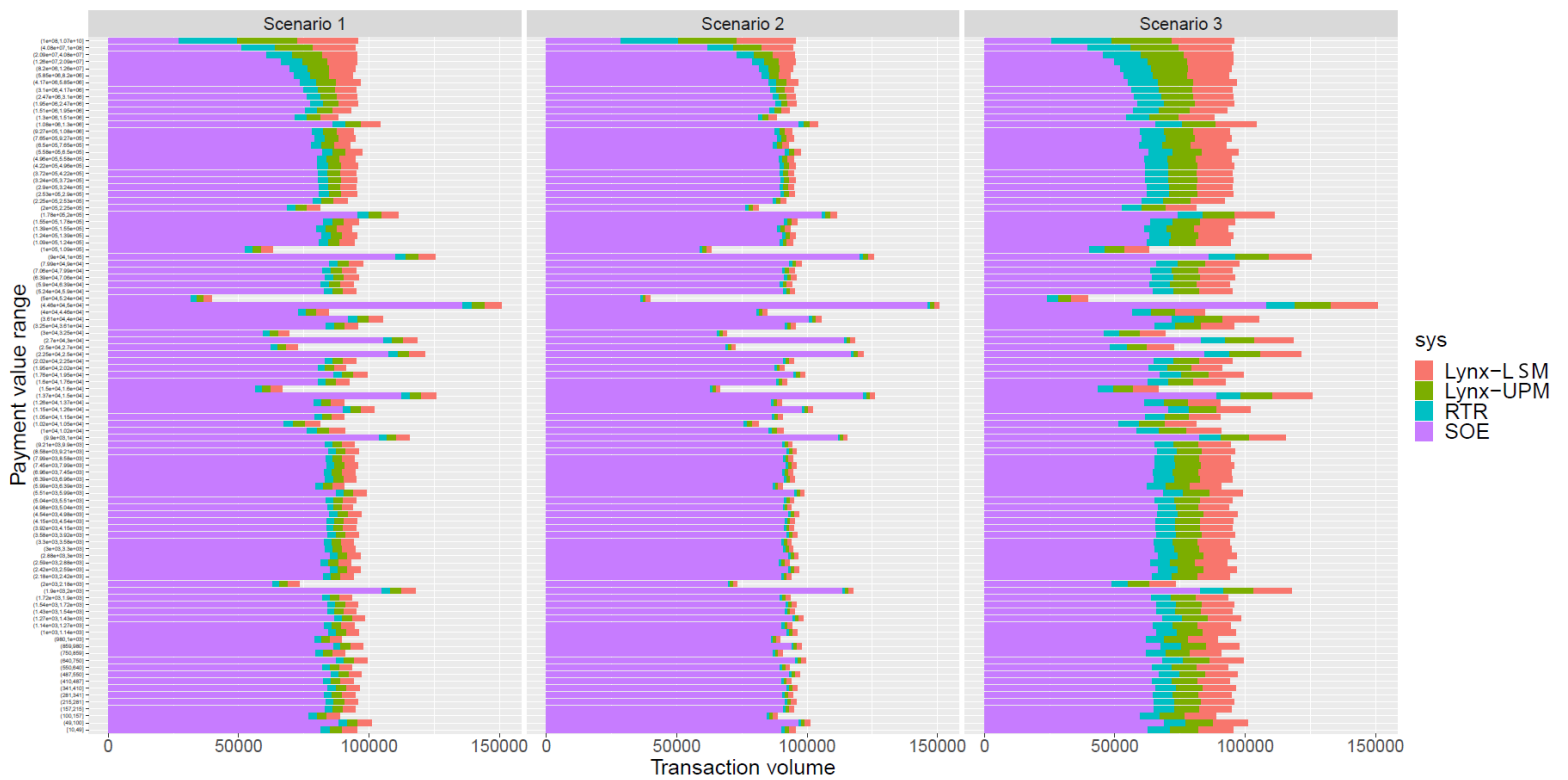

Notes: This graph summarizes the simulated transaction volumes of the future payment systems Lynx (broken down by its two distinct mechanisms Lynx LSM and Lynx UPM), SOE and RTR, for each of the value bins (listed on the vertical axis). This simulation is based on the estimates generated by the binary logit estimation and the scenario assumptions listed in Table 8 . 
Figure 11: Simulated value shares: with caps on SOE and RTR

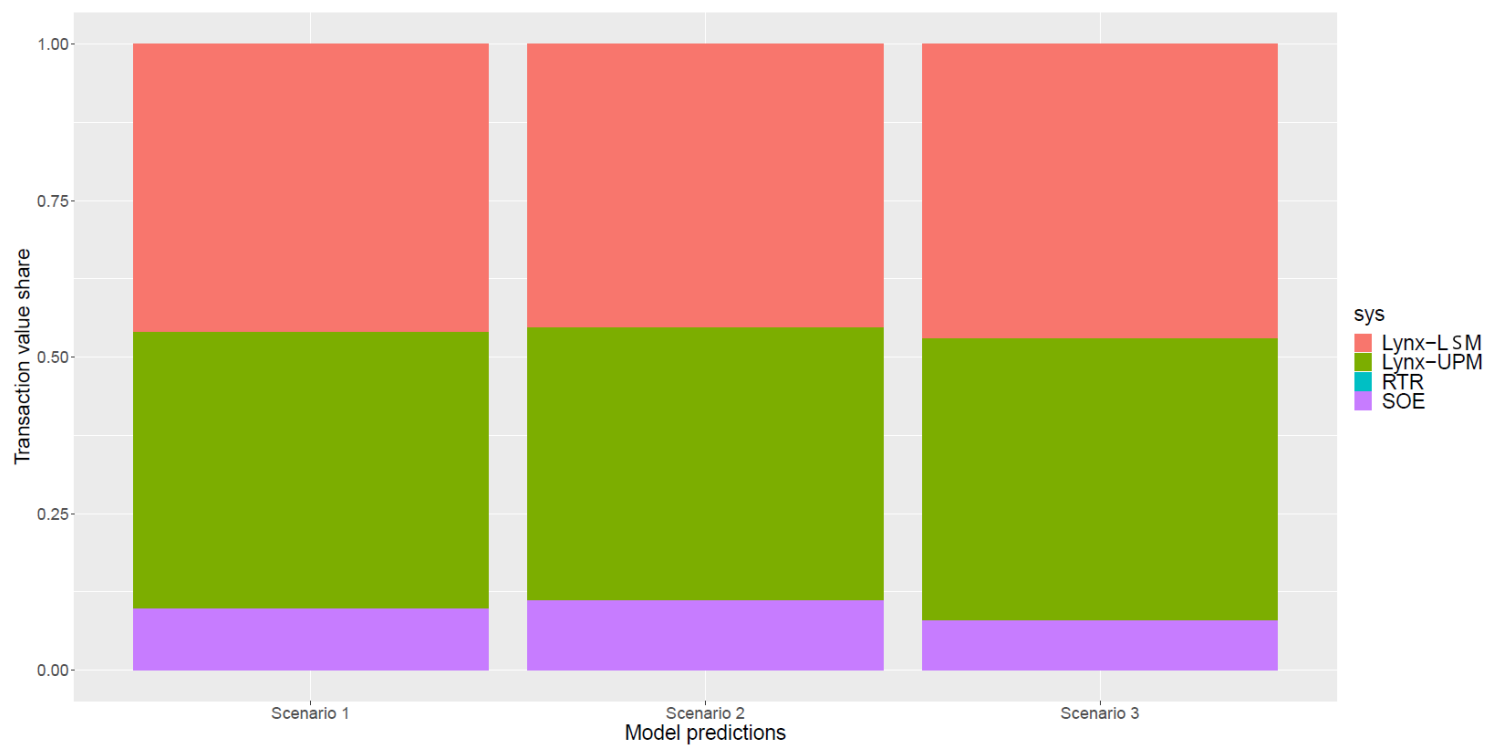

Notes: This graph summarizes the simulated value shares of the future payment systems Lynx (broken down by its two distinct mechanisms Lynx LSM and Lynx UPM), SOE and RTR, while imposing a value cap of CAD 22,000 for RTR payments and a cap of CAD 25 million for SOE payments. The simulations are based on the estimates generated by the binary logit estimation and the scenario assumptions listed in Table 8 
Figure 12: Simulated volumes in Lynx, SOE and RTR: client-driven payments
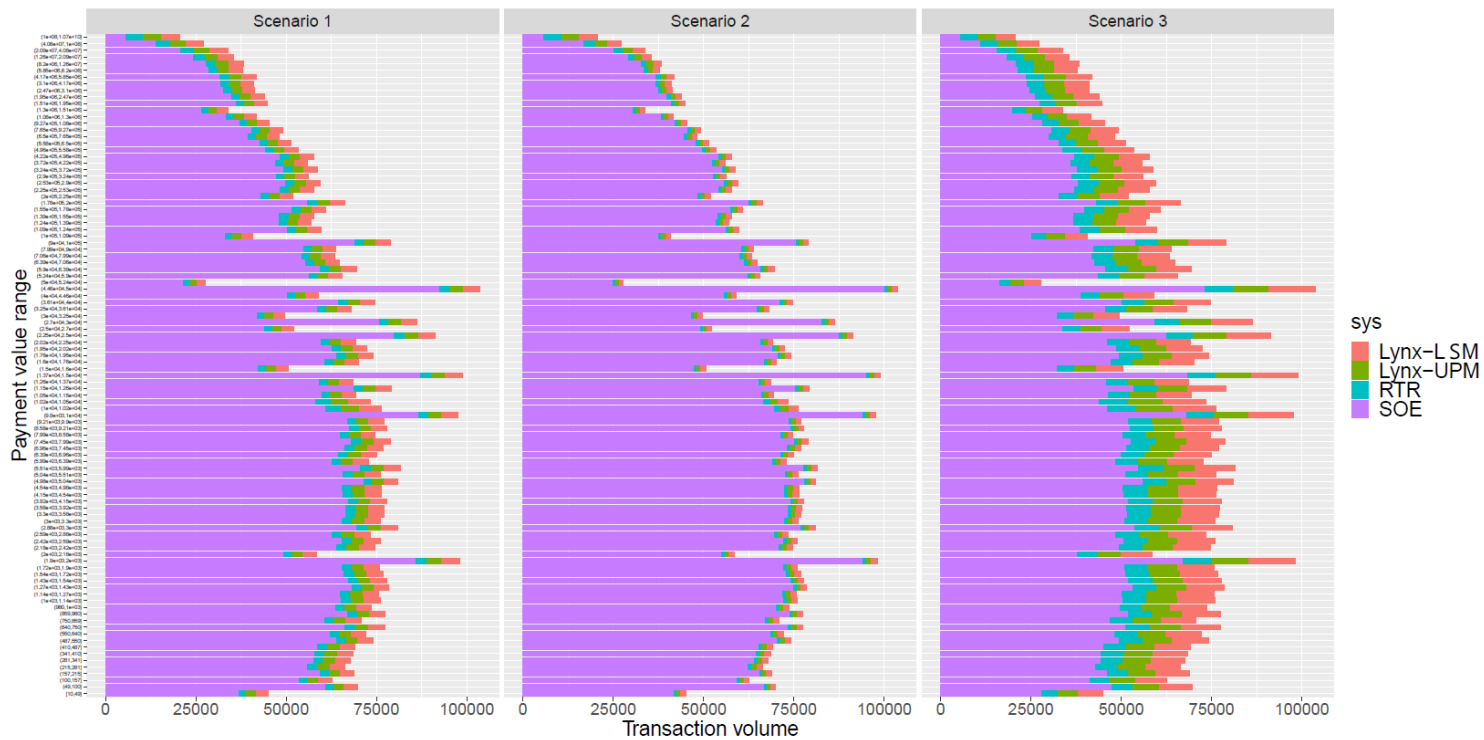

Figure 13: Simulated volumes in Lynx, SOE and RTR: bank-driven payments
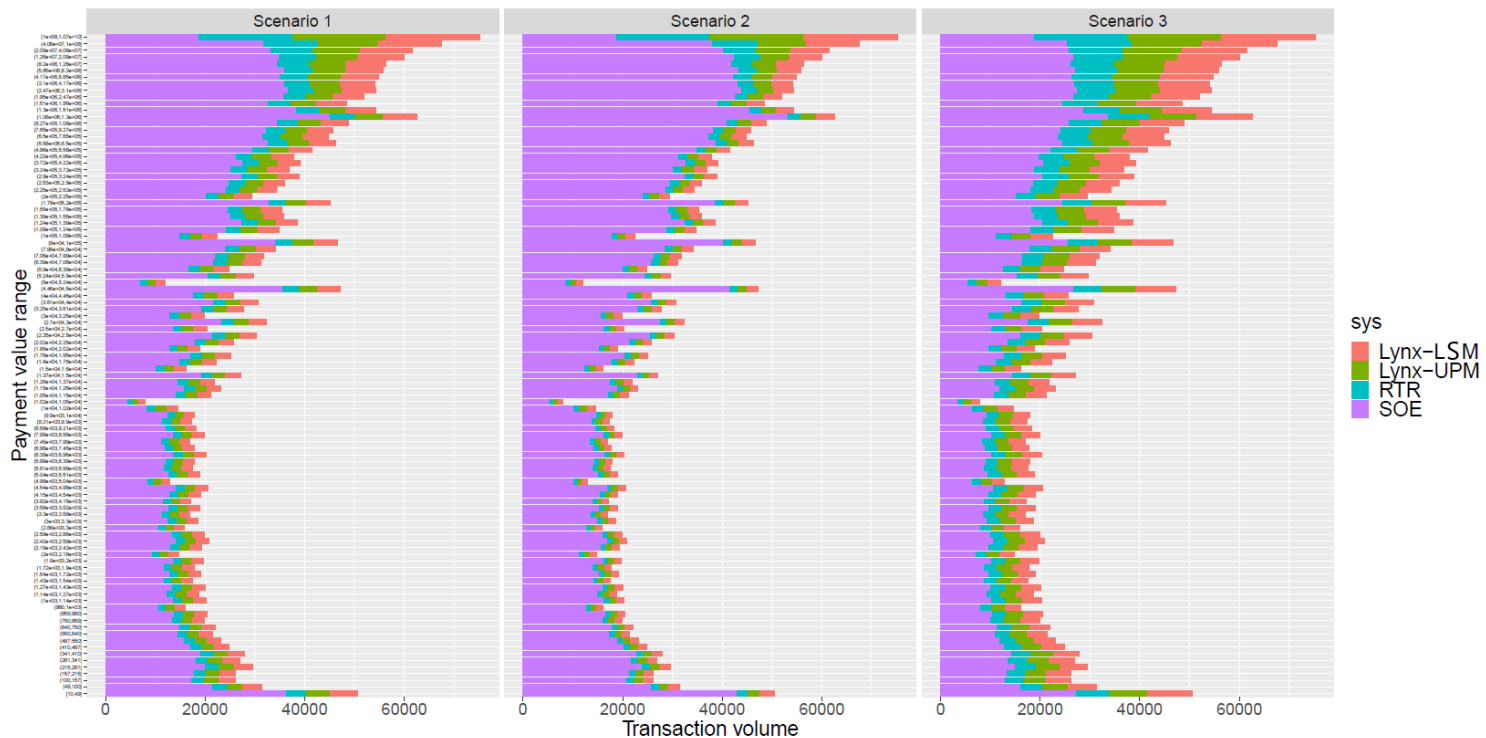

Notes: Figure 12 and Figure 13 summarize the simulated transaction values in each of the value bins of the future payment systems Lynx (broken down by its two distinct mechanisms Lynx LSM and Lynx UPM), SOE and RTR, for client-driven payments and bank-driven payments respectively. The simulations are based on the estimates generated by the binary logit estimation and the scenario assumptions listed in Table 8 
Figure 14: Impact of RTR on end-user payments 2 years after its introduction

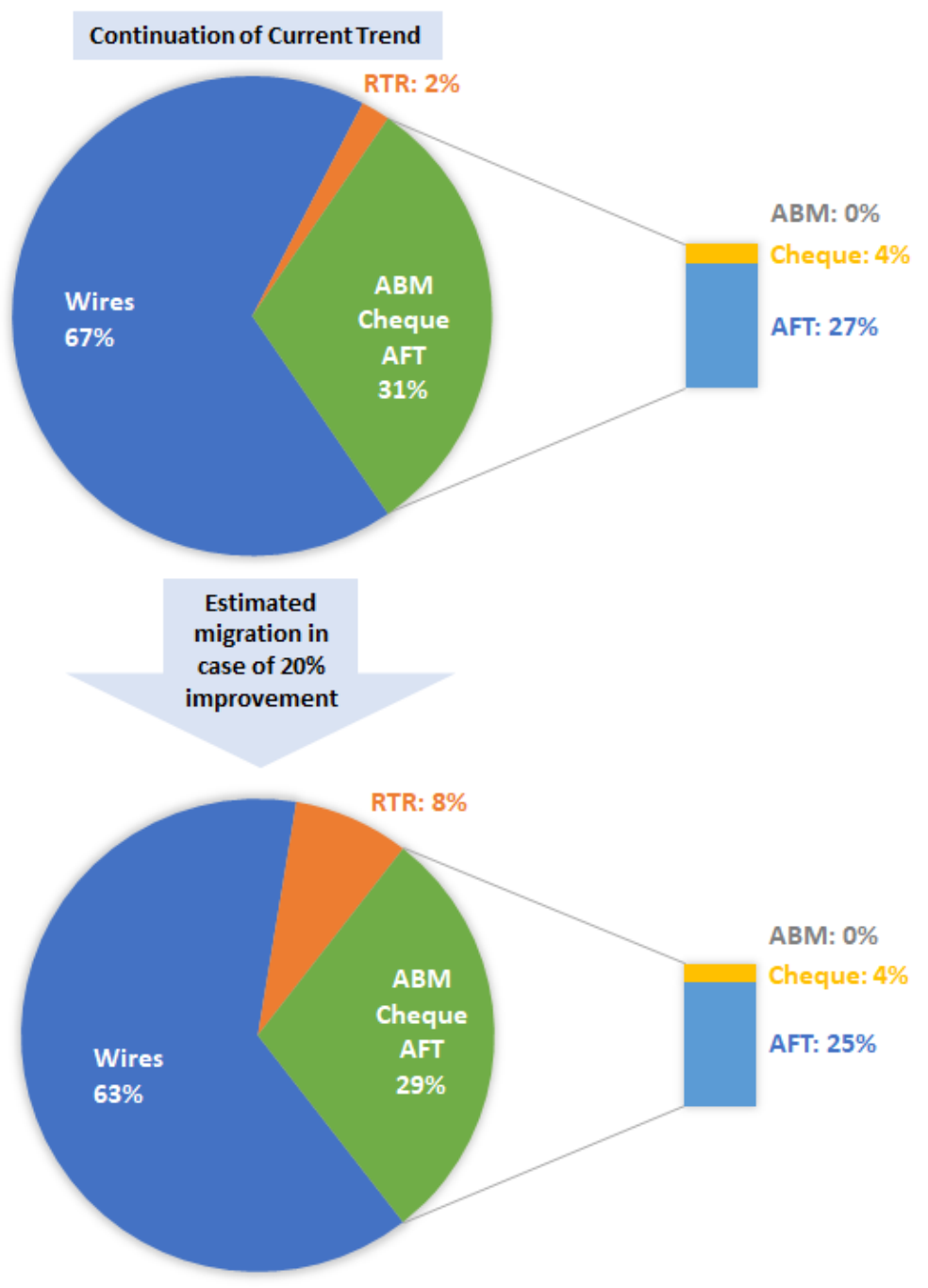

Notes: This figure summarizes the predicted value shares of ABM withdrawals, AFT debit and AFT credit (AFT), cheques, wire transfers and RTR, two year after the introduction of RTR. The predictions are based on the estimation results presented in Table 1. The upper pie represents the "Baseline" scenario, which is an extrapolation of the historical trends with RTR following the same trend as the current Interac e-Transfer. The lower pie represents the "20\% Improvement" scenario, which simulates the future assuming that the payoff of RTR will be $20 \%$ higher than that of the current Interac e-Transfer. 
Figure 15: Summary of migration of current LVTS payments due to financial institutions' preferences

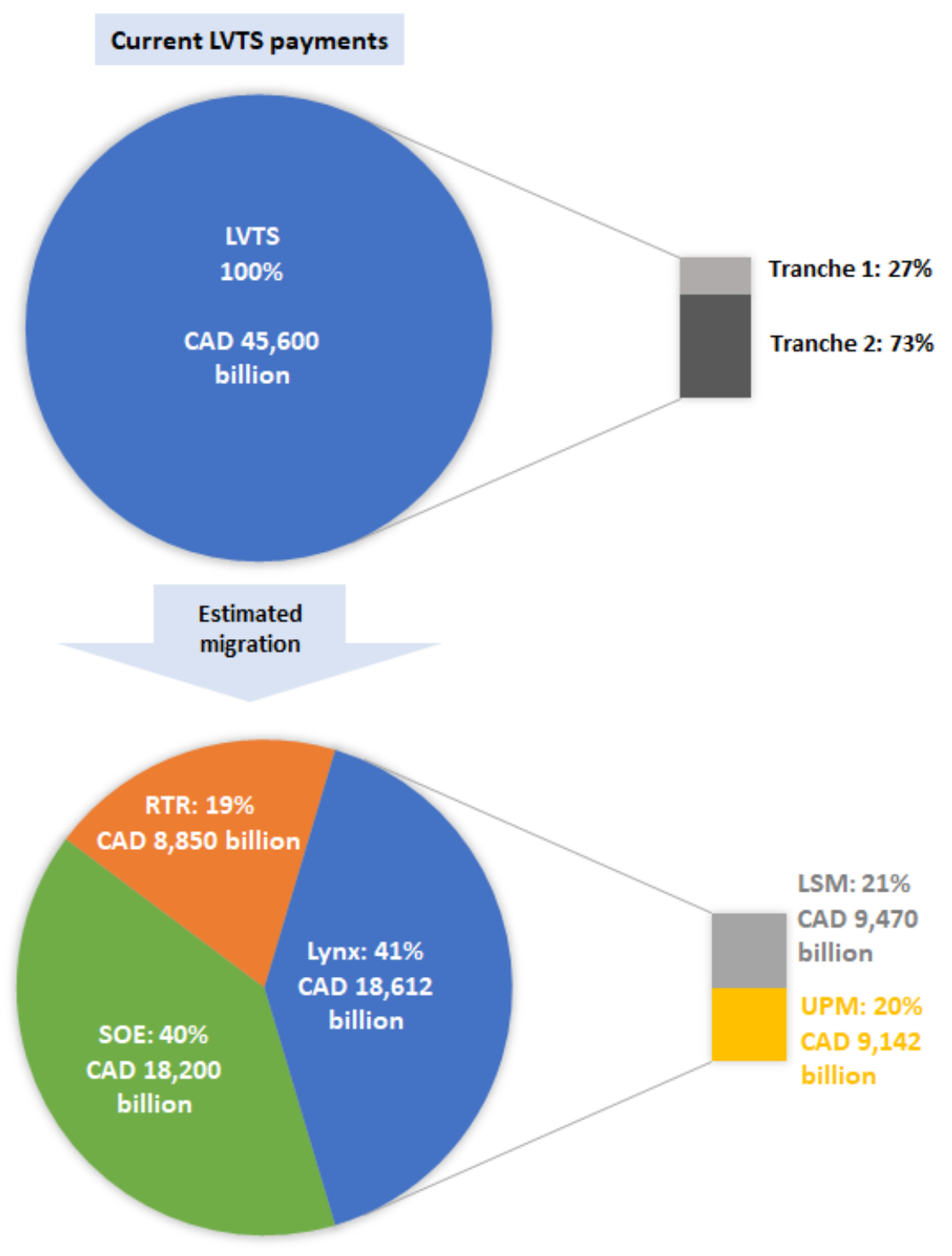

Notes: This graph summarizes the simulated value shares of the future payment systems Lynx (broken down by its two distinct mechanisms Lynx LSM and Lynx UPM), SOE and RTR, using the estimates generated by the binary logit estimation and the Scenario 1 assumptions listed in Table 8 Also, note that the above dollar numbers are based on the total value of payments in the current LVTS system. In the modernized world, as our end-users' demand model predicts, end-users will migrate some wire payments from the current LVTS to RTR. So these wire payments should be deducted from the total value of LVTS payments when interpreting the dollar numbers in the migration results (driven by financial institutions' choices) shown in this graph. 